\title{
Modeling Tunnel Construction Risk Dynamics: Addressing the Production versus Protection Problem
}

\author{
Fan Wanga, b, Lieyun Ding ${ }^{\mathrm{b}}$, Peter E.D. Love ${ }^{\mathrm{c}}$, and David J. Edwards ${ }^{\mathrm{d}}$ \\ ${ }^{a}$ Department of Engineering Safety and Disaster Prevention, \\ Yangtze River Scientific Research Institute, Wuhan 430010, P.R. China \\ ${ }^{\mathrm{b}}$ Department of Civil Engineering and Mechanics, \\ Huazhong Univ. of Science and Technology, Wuhan 430074, P.R. China \\ ${ }^{\mathrm{c}}$ Department of Civil Engineering, Curtin University, \\ GPO Box U1987, Perth, WA 6845, Australia \\ d Faculty of Computing, Engineering and the Built Environment \\ Curzon Street, Birmingham, B4 7XG, UK.
}

Corresponding author: Professor Lieyun Ding

Email:dingly_wuhan@aliyun.com

January 2015 


\title{
Modeling Tunnel Construction Risk Dynamics: Addressing the Production versus Protection Problem
}

\begin{abstract}
Accidents remain a pervasive problem in tunnel construction. A major contributor to these accidents is the construction contractor's inability to determine an appropriate trade-off between production and protection goals. Building upon previous research, a conceptual framework of the relationships between competing organizational goals and various technical risks is proposed. This framework forms the basis for a systemic 'multiple methods' model of the interactions between the contractor's organizational and technical systems as a first step towards mitigating risks posed. Multiple methods are utilized given the complexity of risk factors that influence a system's safety. Specifically, the model integrates System Dynamics (SD), Bayesian Belief Networks (BBN) and smooth Relevance Vector Machines (sRVM) (referred to as 'Organizational Risk Dynamics Observer' (ORDO)). The final model developed is demonstrated on an urban metro tunnel project that was constructed in Wuhan, China. Organizational factors that influence the performance of a safe system of work and the shifting focus of management between production and protection goals are also examined. Findings suggest that when attention focuses upon production, the propensity for minor accidents to occur increased, which triggered management to focus on protection. Moreover, an increasing emphasis on protection may mute the safe systems of working as incidents go unreported thus inhibiting the motivation for safety awareness. When coupled with an increase in production pressure, the tunneling project becomes prone to experiencing a major accident. Therefore, the whole organization must continue to foster a sound safety culture to resist production pressure at the expense of compromising safety.
\end{abstract}

Keywords: Risk modeling; safety management; tunnels; system dynamics; bayesian belief network; smooth relevance vector machine 


\section{INTRODUCTION}

Geotechnical conditions, structures and underground services/ pipelines can pose significant risks during the construction of tunneling projects. Such risks must be controlled to mitigate rework and accidents, and ensure that projects are delivered successfully. Yet, according to Sousa (2010) and Sousa and Einstein (2012) accidents during tunnel construction are frequent and adversely influence project performance. Research undertaken by Flyvbjerg et al., (2002) and Love et al., (2014) identified that cost overruns for tunnel construction projects can range between $20 \%$ to $110 \%$. Examples of infamous tunnel accidents include the Sasago Tunnel (1977) in Japan, Boston's Big Dig (2006) in the United States of America and Hangzhou Metro (2008) in China.

Sousa (2010) classified the underlying causes of tunnel accidents as: internal, external management and adverse geotechnical conditions. These causes are not mutually exclusive because accidents encapsulate an array of circumstances (i.e. technical, managerial and organizational factors) that combine to produce the event (e.g., Perrow, 1984; Reason, 1990; Reason, 1997; Pidgeon, 2000; Dekker, 2006). Construction and engineering projects are complex systems that are bounded by protection and production axes (Reason, 1997; Goh et al., 2012). To ensure projects met performance specifications, organizations often face trade-offs between multiple (and sometimes conflicting) goals, which shape management decisions, policies or strategies (Love and Edwards, 2013; Rasmussen, 1997). Under such circumstances, Howell et al., (2003) observed that an organization's safe system of working can erode from a state of being 'safe' to 'hazard', and to 'loss of control' where safety margins evaporate.

Due to limited prior knowledge of geotechnical conditions, tunnel projects are prone to failures due to collapse and excessive deformation as work progress (Cárdenas et al., 2013). In urban areas, tunneling also elevates the risk of damage to adjacent structures and pipelines (Eskesen et al., 2004). Thus, safety is imperative for contractors during construction despite pressures to meet performance specifications.

Despite advances being made in tunneling technology and safety management measures, 
accidents still prevail. To eradicate tunneling accidents requires a deeper understanding of the underlying dynamics that contribute to a phenomena entitled as strategic project drift (SPD) which elevates the risk of accidents. In the context of this research, SPD represents a movement away form a safe system of working due to schedule pressure and is similar to the 'production versus protection problem (c.f. Marais and Saleh, 2008; Goh et al., 2012). Against this contextual backdrop, this paper first develops a conceptual framework of the relationships between different organizational goals and technical risks that may arise during tunnel construction. Second, a combination of multiple methods is utilized to model patterns that contribute to a project becoming 'unsafe.' A systemic model presented integrates System Dynamics (SD), Bayesian Belief Networks (BBN) and smooth Relevance Vector Machines (sRVM), called Organizational Risk Dynamics Observer (ORDO). The model's application is demonstrated on an urban metro tunnel project that was constructed in Wuhan, China and presents an insightful opportunity to develop effective accident prevention strategies.

\section{SAFETY RISK ANALYSIS FOR TUNNELING PROJECTS: DEVELOPMENT, STIMULI AND CHALLENGES}

A plethora of safety risk analysis models for complex systems have been promulgated over the last 30 years (c.f. Perrow, 1984; Reason, 1997; Rasmusson, 1997; Leveson et al., 2009; Leveson, 2011). Mohaghegh (2007) broadly categorized these models according to their underlying research paradigms as:

i) prescriptive models (early phase) - based upon the defense-in-depth concept, these use multiple safety barriers to achieve a safe system of working. An underlying philosophy is that accidents occur due to an absence or breach of defenses along the accident trajectory (Saleh et al., 2010). However, this concept is heavily reliant upon the identification and prevention of potential accident scenarios;

ii) descriptive models in terms of deviations from norms (first generation) - these focus upon errors or unsafe operations that lead to accident occurrence. Thus, the likelihood of an accident can be calculated using the predefined causal relationships, which arise due to 
adverse events such as human error or technical failure. Examples of such models include fault and event trees (Sturk et al., 1996; Hong et al., 2009; Nývlt et al., 2011), Reason's (1997) Swiss Cheese Model and the BBN technique (Ren et al., 2008). However, explanation of an accident in terms of events has been criticized for not being able to incorporate complex relationships such as delays and feedbacks (e.g. Rasmussen, 1997; Leveson, 2004). BBNs are also unable to reveal the underlying pattern that drives systems toward risks when subjected to cost-effectiveness pressure (Rasmussen, 1997; Leveson, 2004). Rasmussen (1997) recognized the limitations of descriptive models and noted that "it is evident that a new approach to representation of system behavior is necessary, not focused on human errors and violations, but on the mechanisms generating behavior in the actual, dynamic work context."; and

iii) descriptive models in terms of actual behavior (second generation) - these emphasize the systemic and collective nature of system behavior. Accidents are described as an emergent phenomenon that arise from the interactions between multiple agents within a socio-technical system. Examples of descriptive models include the Systems-Theoretic Accident Model and Processes (STAMP) model (Leveson, 2004), where safety is treated as a control problem and managed by a control structure embedded in an adaptive socio-technical system.

Although systems-based methods have been used for accident analysis or risk assessment (e.g., Goh et al., 2010; Goh et al., 2012b; Ouyang et al., 2010; Salmon et al., 2012), only a small number have been developed for construction and engineering projects (Mitropoulos et al., 2005; Kazaras et al., 2012). Moreover, most systems models were qualitative thus preventing quantitative risk analysis. Recent representatives of quantitative safety risk models include STAMP (Dulac et al., 2005, Socio-Technical Risk Analysis (SoTeRiA) (Mohaghegh and Mosleh, 2009; Mohaghegh et al., 2009) and Traffic Organization and Perturbation AnalyZer (TOPAZ) (Stroeve et al., 2009; Stroeve et al., 2011), which uses one or more techniques, such as SD, BBN, Monte Carlo simulation and agent-based simulation, to model the system risk.

\section{Stimuli of establishing a systemic safety risk model}


Safety risk models used for tunnel construction are generally derived from the first-generation which recall the accident scenario to assist in the assignment of blame (e.g., Nývlt et al., 2011; Cárdenas et al., 2013). Punishment however, is not an effective strategy for learning from, or preventing future accidents (Dekker, 2011). Evidence reveals that even when people are dismissed for their mistakes, similar accidents may occur as the organizational and management settings that drive behavior remain unchanged (Ouyang et al., 2010). Whether second-generation safety risk models for tunnel projects are necessary depends on the goal of analysis, for example, to engineer a safer system that focuses upon mechanisms vis-à-vis causes (Leveson, 2004; Le Coze, 2013).

\section{Challenges of moving toward a second-generation model}

Numerous calls to propagate innovative ideas on safety risk analysis (Leveson 2004; Mohaghegh, 2007; Kyriakidis et al., 2012) have produced frameworks that expand our understanding of risk (e.g., Mohaghegh and Mosleh, 2009; Stroeve et al., 2009). However, the complexity and multi-disciplinary nature of safety issues has created a lag between theoretical advancements and the development of methods and techniques with which to implement these (Pasquini et al., 2011). Consequently, three major challenges have impeded progression from first to second generation safety risk models:

\section{From proximal factors to distal factors:}

Analysis of major accidents indicates that accident prevention must shift from a 'technical' (i.e. proximal causes) to an 'organizational' (i.e. distal antecedents and contributors causes) focus (Perrow, 1984; Reason, 1997; Kennedy and Kirwan, 1998). Because organizational factors are pivotal in almost all accidents, the organization provides a promising way for improving safety and for better understanding the 'context' of accidents (Le Coze, 2005; Leveson et al., 2009). Yet, few models explicitly encapsulate the impact of organization and management on safety performance (Mohaghegh et al., 2009). For example, whilst classical probabilistic risk assessment (PRA) approaches quantify the mathematical probabilities and severities of system failures, they generally fail to incorporate organizational aspects that lead to failure (Bier 1999; Apostolakis, 2004). In part, this gap exists because technical and organizational systems are 
dissimilar. Organizations are open and contain non-linear causalities which need systemic approaches to analyze, whereas technical systems are closed and linear causalities present can be studied using analytical methods (Le Coze, 2005). Tunneling projects are a socio-technical system and their performance is determined by the interaction between the physical construction processes and organizational elements. Therefore, integrating technical and organizational systems into one single model is critical to accurately determining the organizational risk factors or management shortcomings that elevate safety risk.

\section{From static analysis to dynamic modeling}

Most risk analyses are 'static' and focus on addressing the probabilities and consequences of accidents at a single point in time (e.g., Nývlt et al., 2011; Qu et al., 2011). However, tunneling works are dynamic processes where organizations involved are continually adapting in response to the prevailing external environmental and local pressures (Marais et al., 2004; Leveson, 2011). Accidents are therefore not the immediate result of a discrepant event, but rather a cumulative effect of various causes over an incubation period (Turner and Pidgeon 1997; Pidgeon and O'Leary, 2000). Moreover, unlike highly complex nuclear or petrochemical industries which have tightly-coupled systems, tunneling projects are highly-complex but loosely-coupled (Perrow, 1984). Loosely coupled systems have fewer tight links between components, do not respond quickly to perturbations and may contain time delays. These characteristics can conceal incidents that indicate that a system has transitioned into a hazardous state (Marais et al., 2004; Lofquist, 2010). Therefore, describing a system's dynamic characteristics is a precondition for revealing the mechanism of migration toward increasing risks.

\section{From reductionism to holism}

A holistic perspective views a system as being more than the sum of its parts (Le Coze, 2005). For example, the safety of a shield-driven tunnel cannot be understood by merely evaluating the performance of a shield machine and operators but rather the human-machine interaction in the context of a dynamic environment, taking into consideration organizational and technical aspects (Leveson, 2009; Leveson, 2011). Therefore, a systemic safety risk model cannot be built by a 
bottom-up aggregation of sub-models, but a top-down approach based on the concept of system thinking. Such a model has yet to be developed for tunneling works.

\section{A SYSTEMS FRAMEWORK FOR SAFETY RISK MODELING IN TUNNELING}

Organizations can be examined at a number of levels (e.g. micro, meso and macro) that focus on the individual, intra-organizational and inter-organizational behaviors or relations respectively (Stroeve et al., 2011). Modeling complex organizations using system theory can enable hierarchical levels to be sub-divided with control processes operating at the interfaces between them (Rasmussen, 1997). Thus, Rasmussen and Svedung (2002) and Leveson (2004), have proposed similar safety control models that incorporate a hierarchical structure with embedded social and organizational levels that interface with hazardous processes. Upper levels influence lower levels by laws, regulations, policies - while lower levels provide information and knowledge for the upper levels to make appropriate decisions. Higher levels require more time to make change (e.g. to pass safety legislation) whilst conversely, lower levels focus upon changing individual behaviors by referring to manuals or learning from past experiences.

Figure 1 presents a conceptual framework for modeling risk in a tunnel project that is based upon a synthesis of former extant literature. The framework consists of five core components, namely: i) safety culture; ii) safety management practices; iii) safety performance and feedback; iv) the interaction of safety and other organizational goals; and v) modeling techniques applied to different modules.

\section{Safety culture}

Although no universally accepted definition for safety culture exists (Guldenmund, 2000), there appears to be commonality amongst the numerous definitions quoted within the literature (Wiegmann et al., 2002). For example, Choudhry et al. (2007b) defined construction safety culture as: "the product of individual and group behaviors, attitudes, norms and values, perceptions and thoughts that determine the commitment to, and style and proficiency of, an organization's system and how its personnel act and react in terms of the company's on-going safety performance within construction site environments." Contrastingly, Zou (2011) offered an 
alternative definition as: "an assembly of individual and group beliefs, norms, attitudes, and technical practices that are concerned with minimizing risks and exposure of workers and the public to unsafe acts and conditions in the construction environment." Several studies have sought to identify and measure the dimensions of safety culture (Guldenmund, 2000), and whilst the number of dimensions differ (Guldenmund, 2000), management commitment to safety and safety performance are leitmotiv's among these studies (e.g., Zohar, 1980; O'Toole, 2002; Mohamed, 2003; Fernández-Muñiz et al., 2007a; Brooks, 2008). Management commitment to safety is a determining factor that shapes management practices (Zou, 2011). For this paper, Mohaghegh et al.'s (2009) approach is adopted whereby management commitment to safety is used as a measure of safety culture.

\section{Safety management practices}

Safety management practices are a systematic and explicit approach to managing risks and hazards by organizing people, resources, policies and procedures interactively to reduce risk (Edwards, 1999; Fernández-Muñiz et al., 2007b; Dağdeviren and Yüksel, 2008). Thus, during tunnel construction, different counter-measures must be identified and accounted for to prevent undesired event occurrance. However, the constituent components of good safety management practice has, and remains a topic for much discussion (e.g., Santos-Reyes and Beard, 2002; Grote 2012). From the literature, suggested components of good safety management synthesized and reproduced in Table 1 and notably some factors, such as safety training and education, are found replicated several times. Human resources are the mainstay of construction organizations, and education and training is pivotal to improving safety (Zou, 2011). However, economic perturbations and high employee turnover presents an on-going challenge for construction contractors that seek to implement effective safety education and training (Clough et al., 2000). 


\section{Safety performance and feedback}

Accident data is frequently used to measure an organization's safety performance yet such data present lagging indicators that provide 'hindsight' not 'foresight' (Dyreborg, 2009). Leading indicators (foresight - such as near misses) provide useful predictors of safety performance levels because they observe weaknesses ahead of a serious incident occurring (Hinze et al., 2013). Safety cannot be ensured by counting lagging indicators only, rather continuous monitoring of lagging indicators of past deficiencies and leading indicators of organizational processes and technical conditions are required (Reiman and Pietikäinen, 2012) Therefore, both the risk level and accident severity are adopted as leading and lagging indicators of safety performance respectively, and the counter-measures are classified into proactive measures and reactive measures in response to the two types of safety outcome (Lofquist, 2010).

Counter-measures designed and implemented in response to safety performance can be seen as a learning process (Bellamy et al., 2008). For example, the adjustment of shield operational parameters to control tunneling-induced ground deformation risk level. However, learning by merely reacting to undesired outcomes (as per single loop learning (Agyris and Schon, 1996)) fails to adequately address individuals' safety attitudes and awareness or organizational culture. This learning process is 'controlling oriented' as actions are modified based on the mismatch between desired outcomes and reality to minimize variation and avoid surprises (Carroll et al., 2002). Instead, a deeper organizational learning strategy (e.g. double loop learning (Agyris and Schon, 1996)) is necessary to promote a sustainable positive safety culture (Pidgeon and O'Leary, 2000; Sorensen, 2002; Choudhry et al., 2007b). Double loop learning is referred to as 'rethinking oriented' as the appropriateness of goals or basic cultural assumptions are challenged (Carroll et $a l .$, 2002). The major difference is that single-loop learning takes place under an organisation's existing standards or norms, while the double-loop learning is the learning of standards or norms per se and requires more time to realize (Stäbler and Ewaldt, 1998).

\section{The interaction of safety and other organizational goals}

A recursive relationship exists between safety and production performance (Mohaghegh and 
Mosleh, 2009). For tunneling projects, safety can influence cost and schedule performance, as accidents may result in financial losses and delays. Love et al. (2004) and Wanberg et al., (2013) found that the occurrence of construction rework adversely impacts upon cost, schedule and safety performance. Thus, safety culture is often negatively influenced when production pressure becomes a primary driver within organizations (Atak and Kingma, 2011). Accordingly, Reason (1998) has stated that: "the cultural accommodation between the pursuits of these goals of safety and production must achieve a delicate balance."

\section{Modeling techniques applied to different modules}

Conventional methods used to perform technical risks analysis include Hazard and Operability Study (HAZOP) (Pérez-Marín and Rodríguez-Toral, 2013) and Failure Mode and Effect Analysis (FMEA) (Mandal and Maiti, 2014). Yet, these techniques cannot capture the interaction and complexity associated between the organizational and technical systems or provide adequate analysis of organizational safety risks (Øien, 2001; Le Coze, 2005; Kongsvik et al., 2010). These aforementioned conventional analytical approaches tend to decompose the system (i.e. installation, plant and infrastructure) into parts and identify what cause-effect relationships produce hazardous sequences. Consequently, the recursive relations in organizations cannot be appropriately examined using them (Le Coze, 2005). Essentially, the dynamics at a project's meso-level can be aggregated to micro and macro levels to enable the 'bottom-up' to meet 'top down' (Goldstein, 2010). In addressing this issue, SD can simulate interactions, decision-making processes and behaviors of a system at these various levels over a period of time (e.g., Sterman, 2000; Goh et al., 2012; Stroeve et al., 2011). According to Goh et al. (2010) and Goh et al., (2012b) safety can be modelled at all levels as it forms part a project's belief system and is embedded within an organization's processes. Moreover, tunnel construction projects often experience unexpected events that may not immediately result in an accident but contribute to strategic drift toward a state of elevated accident risk (Love et al, 2002).

The technical system in a tunnel construction project encapsulates tunneling processes and its impact upon surroundings. Physical tunneling processes can be modeled using finite element 
model (FEM) (Kasper and Meschke, 2004). To control the scale of computation, a fast feedforward interpolator based on smooth Relevance Vector Machine (sRVM) for shield steering is applied (Ding et al., 2013; Wang et al., 2013b). The risks of tunneling-induced damage to existing properties were assessed using the Bayesian Belief Networks (BBN) (Wang et al., 2013a). Developing two models facilitates an estimate of risk levels and accident severities to be made; both of which are indicators of safety performance. In other words, safety performance is modeled beyond the SD environment.

To investigate a tunneling project's migration toward high risk, the SD models for the organization and technical systems are directly linked to simulate their dynamic interactions. The sRVM and BBN are then embedded into the SD environment to facilitate the exchange of data and enable modeling of the entire system. The proposed risk model is referred to as the Organizational Risk Dynamics Observer (ORDO) (refer to Figure 2) and is now discussed.

\section{CASE EXAMPLE: A METRO TUNNEL CONSTRUCTION}

An urban metro tunnel project constructed in Wuhan, China is used to develop the algorithms presented and analytical approach adopted in this research. The project has two lines (refer to Figures 3 and 4) which were constructed using a shield-driven machine which removes soil directly from the excavation face. To stabilize the excavation face and avoid tunnel settlement/ collapse (Maidl et al., 2012), the pressure provided by the shield machine must remain in equilibrium with the external earth pressure. Other nearby risks included damage to adjacent facilities and structures and therefore risk influencing factors (RIFs) needed to be identified by the contractor (Wang et al., 2013a). Ground surface settlement markers were installed above the tunnel's centre line to effectively monitor and control potential risks. The first $100 \mathrm{~m}$ of excavation was used to adjust the shield parameters to a suitable level according to the soil response and so consequently, settlement markers were deployed at $15 \mathrm{~m}$ intervals. The remaining $1100 \mathrm{~m}$ of tunnel thereafter deployed settlement markers at $30 \mathrm{~m}$ intervals.

The model developed was applied to construction of the line 1 tunnel which is $1.2 \mathrm{~km}$ long and 
has an average cover depth ranging from 10 to $15 \mathrm{~m}$ within predominantly clay soil. The tunnel was expected to be completed in 90 days at a cost of 267 million Chinese Yuan (CNY). Various sources of information generated during tunneling works were used for the ORDO model's development (c.f. Figure 1); this information comprised of:

- $\quad$ Field instrumentation data on ground surface settlement that were recorded daily near the excavation face;

- $\quad$ Shield-machine operational parameters were continually monitored and included advance speed, earth pressure and grout filling;

- Geological and geometrical parameters such as soil types at the tunnel crown and invert, cover depth and invert to water table; and

- $\quad$ Adjacent structures and pipelines properties such as foundation depth and type, structure height, diameter of pipelines obtained from investigation documentation ( $c f$. Figure 3).

Using said data, the contractor determined major risks and their significance each day as a means of identifying safety counter-measures required. The contractor's costs (amounting to 240 million CNY plus $10 \%$ for overheads/ profit) were based upon monthly tunnel completion rates.

\section{Model development using hybrid modeling techniques}

The model's development commences by integrating organizational processes and technical systems into one model to run the simulation.

\section{Modeling of organizational processes}

The organizational processes simulated in the SD environment involved four modules: i) management commitment to safety; ii) safety management practices; iii) finance; and iv) schedule.

- $\quad$ Management commitment to safety module

The module of management commitment to safety (Figure 5) is adapted from the work of 
Mohaghegh et al.,'s (2009). The level of management commitment to safety was limited to an inverse linear scale of 0-100, where: 100 denotes the highest management commitment to safety; and 0 denotes the highest management commitment to production - the initial value is set to equilibrium (i.e. 50) at the outset of tunneling works. The tunnel works for each month is planned according to prevailing schedule pressure, which will indicate a demand for sufficient financial support. If production targets cannot be achieved due to financial pressure, management tend to emphasize on production which is positively influenced by the financial pressure (Goh et al., 2012). Consequently, the level of management commitment to safety tends to reduce.

\section{- $\quad$ Safety management practices module}

The safety management practices module is shown in Figure 6. High staff turnover rates in the construction industry (Clough et al., 2000), has underlined the importance of hiring new workers to achieve desired production rates. Hiring involves a process of attempting to reduce the gap between the current average worker workload and the reference workload defined by regulations. Note that a time lag is associated with the hiring process. Labor hiring and resigning processes also creates perturbations if workforce experience levels. To maintain competition and obtain better safety performance, construction companies may provide extensive staff training to maintain organizational performance; where the level of investment is inextricably linked to management commitment to safety. Training does have its cost in terms of direct capital investment and in-direct downtime needed to learn and absorb new skills and knowledge (refer to Figure 6).

Implementing counter-measures is also a task of safety management practices. In practice, some workers are assigned to complete regular periodic maintenance works as the shield-machine advances (Edwards et al., 2003). In addition, various risk levels and accident severities require different amounts of preventive or postmortem measures, such as employing more labor or extending time required to fix a problem (i.e. single-loop learning). Therefore, workers must implement counter-measures in addition to regular 
works; this creates a backlog of safety tasks needed and can exceed the acceptable workload of workers. This backlog affords a measure of fatigue, which may reduce working capacity, cause operation error and reduce human performance (Rasmussen et al., 1990). Implementation these safety tasks is a managerial decision. When demand on safety workload exceeds the reference workload, management must decide whether safety tasks are first fulfilled regardless of the potential influence on production progress.

- $\quad$ Schedule module

Safety can influence a project's schedule and vice-versa (refer to Figure 7). The shield-machine drills in between periodic scheduled maintenance and lining installation. Tunnel works are paid monthly according to production progress therefore, expedient excavation leads to greater recovery of payment. Advance speed is thus an important shield parameter because it determines payment and affects the schedule pressure that contributes to the change of management commitment to safety.

- $\quad$ Finance module

Interactions also exist between safety performance and financial status (refer to Figure 8). Because income is inextricably linked to schedule completion rates each month which in turn, requires sufficient financial support. Safety performance can also affect financial performance by way of compensation for accidents arising; where cumulative losses are related to accident severity and frequency.

\section{Modeling of technical systems}

The technical systems, which output the safety performance, consisted of two parts: i) shield tunneling processes; and ii) risk assessment.

\section{- $\quad$ Shield tunneling processes}

Shield tunneling is a control process that outputs desired products (e.g. metro tunnel) and by-products (e.g. tunneling-induced ground settlements) by inputting various parameters. A 
monumental challenge involves ascertaining and controlling the development of ground surface settlement together with any potential collateral damage incurred. However, due to the complex and non-linear shield-ground interaction, numerous factors affect settlement and hence, an accurate prediction and control method is needed for steering shield tunneling.

To model ground surface settlement development, a dynamic and real-time prediction method is adopted. The present settlement at a specific settlement marker $s_{\mathrm{t}}$ and affecting factors $\mathbf{F}$ are used as model inputs to predict the next settlement $s_{\mathrm{t}+1}$, and the actual measurement of the next settlement is then taken as the present settlement for the next prediction. That is:

$$
s_{t+1}=f\left(s_{t}, \mathbf{F}\right)
$$

Factors that affect ground surface settlement can be categorized into three groups: i) tunnel geometry (e.g. cover depth and distance from excavation face to settlement markers); ii) geological conditions (e.g. soil types at tunnel crown and invert, and water table); and iii) shield operational parameters (e.g. advance speed, earth pressure and grout filling). The shield-ground relationship $f(\cdot)$ is established using a smooth relevance vector machine, which is a specialization of a sparse Bayesian model (Schmolck and Everson, 2007; Tipping, 2001). Therefore, the relationship between the affecting factors and settlement is obtained by training the model using collected data samples.

Based on the established shield-ground relationship, the shield operational parameters can be optimized to control the development of settlement, thus a feedforward interpolator (cf. Ding et al., 2013; Wang et al., 2013b) is formed (refer to Figure 9).

\section{- $\quad$ Tunneling risk assessment}

A contractor must assess the major risks prior to, and during tunneling so that risk mitigation measures can be designed and implemented. Wang et al., (2013a) proposed a 
hierarchical framework to describe the risk propagation from the RIFs to the final risks; Bayesian belief networks were then applied to formalize the framework. Historical data and elicited expert domain knowledge are combined to quantify the final model. This approach (ibid) allowed risk scenarios to be identified and the probabilities associated with these to be calculated (cf. Kaplan and Garrick, 1981). The risk assessment model's structure is presented in Figure 10.

To determine the risk level, the decision matrix risk-assessment (DMRA) method is adopted because it can differentiate relative risks to facilitate consistent decision-making (Marhavilas et al., 2011). During tunneling works, the frequency of occurrence and severity of consequences are classified (cf. Tables 2 and 3). The risk criteria are presented as a risk matrix considering the two parameters of risk magnitude (Figure 11). The DMRA method compares the assessment results to the risk matrix to determine the risk level (negligible, acceptable, unwanted and unacceptable), which is subsequently used to guide further actions (Table 4) (cf. Wang et al., 2013a).

\section{Linking organizational processes and technical systems}

The ORDO model's structure (see Figure 12) consists of different modules that are integrated to run the simulation as a single model. These modules are now further elucidated upon.

- $\quad$ Tuning the advance speed ( $\operatorname{Link} A)$

Advance speed is a critical factor that relates to tunneling safety and production. In this research, adjustment of the shield operational parameter acts as a trigger to denote the contractor's efforts to balance safety and production goals in equilibrium. Fast tunnel boring can elevate risks posed and therefore, the optimized advance speed (which aims to control settlement development) represents safety-oriented speed $V_{\mathrm{s}}$. Conversely, schedule pressure requires a minimum advance speed which represents production-oriented speed $V_{\mathrm{p}}$. This research assumes that the decision on setting of the parameter $V$ is a linear combination of the safety-oriented and production-oriented decisions, which gives: 


$$
\left\{\begin{array}{lll}
V=V_{s} \cdot C / 100+V_{p}(1-C / 100) & \text { if } & V_{s}<V_{p} \\
V=V_{s} & \text { if } & V_{s} \geq V_{p}
\end{array}\right.
$$

where $C$ : is the level of management commitment to safety (on a scale of $0-100$ ). Once advance speed is tuned, ground surface settlement and shield parameters optimization can be analyzed.

- $\quad$ Inferring the RIFs (Link B)

The differential settlement of structures and pipelines are critical RIFs contributing to tunneling risks (Wang et al., 2013a). In this research, the differential settlement is inferred based on the predicted ground surface settlement, for example, Figure 13 illustrates tunneling-induced damages to adjacent structures. The inclination $\delta$ can be calculated using Eq. (3):

$$
\delta=\xi \frac{\Delta s}{L}
$$

Where: $\Delta s$ is the differential settlement; $\xi$ is the reduction coefficient which depends upon the structure's stiffness; and $L$ is the length of the structure perpendicular to the tunnel alignment. If the ground surface settlement above the tunnel center line $S_{\max }$ is given, $\Delta s$ can be approximated using Peck's formula (Peck, 1969):

$$
\Delta s=S_{B}-S_{A}=S_{\max } \exp \left(-\frac{x^{2}}{2 i^{2}}\right)-S_{\max } \exp \left(-\frac{(x+L)^{2}}{2 i^{2}}\right)
$$

Where: $x$ is the lateral distance from the tunnel alignment to the structure; $i=k Z$ is the inflection point; and $Z$ is the tunnel depth. The value for $k$ is taken as 0.5 for cohesive soils and 0.25 for granular soils. Once all RIFs are quantified, risks assessment commences using the risk assessment model. 
- $\quad$ Safety performance indicators feedback to organizations (Link C)

The risk level and accident severity are two indicators of organizational safety performance. Different risk levels and accident severities require alternative amounts of remedial works (single-loop learning) and lead to bespoke levels of safety pressure that impacts the management commitment towards safety (double-loop learning). To model the influence of accidents, accident severity is simulated based on the assessed probabilities and consequences of a hazard, and the accident caused losses in Figure 8 is determined according to Table 3 .

- $\quad$ Safety management practices influence safety performance (Link D)

Safety management practices impact upon the effectiveness of counter-measures employed (i.e. are such measures implemented appropriately and timely). This can be determined via the average experience of workers and backlog of counter-measures implemented. Without available data for this aggregation, expert knowledge is exploited using fuzzy logic to calculate the fuzzy membership of the states of effectiveness for counter-measures (Taroun et al., 2011), and the membership degree is then transformed to the probability using Eq. (5) (Singpurwalla and Booker, 2004):

$$
P\left(x \in \tilde{A} ; m_{\tilde{A}}(x)\right)=\left(1+\frac{\mathcal{L}\left(x \notin \tilde{A} ; m_{\tilde{A}}(x)\right) P(x \in \tilde{A})}{\mathcal{L}\left(x \in \tilde{A} ; m_{\tilde{A}}(x)\right) P(x \notin \tilde{A})}\right)^{-1}
$$

Where: $P\left(x \in \tilde{A} ; m_{\tilde{A}}(x)\right)$ is the probability that classifies $x$ as being in the fuzzy set $\tilde{A}$ with the fuzzy membership; $m_{\tilde{A}}(x) ; \mathcal{L}\left(x \in \tilde{A} ; m_{\tilde{A}}(x)\right)$ is the likelihood of $x$ for a specified $\tilde{A} ; P(x \in \tilde{A})$ is the probability that nature classifies $x$ as being in $\tilde{A} ; \frac{\mathcal{L}\left(x \notin \tilde{A} ; m_{\tilde{A}}(x)\right)}{\mathcal{L}\left(x \in \tilde{A} ; m_{\tilde{A}}(x)\right)}$ indicates the likelihood ratio of membership function; and $\frac{P(x \in \tilde{A})}{P(x \notin \tilde{A})}$ is the prior odds. Because there is no prior knowledge for the classification, the prior odds are set to 1 in the model. 
By linking the organizational process and the technical system, different modules are integrated into a single model. However, because modules are run in different software environments, Microsoft Excel is used for importing and exporting data.

\section{MODEL EVALUATION}

The proposed feedforward interpolator was validated in a previous metro tunneling project (Ding et al., 2013; Wang et al., 2013b). Mean squared error (MSE) and mean absolute percentage error (MAPE) measures of evaluation were adopted to assess prediction capacity, whilst the relative importance of factors identified by the model was compared via sensitivity analysis. Results indicated that the model performed well and the method of adjusting the shield operational parameters based on the established model was also feasible.

The BBN model was also applied to a metro tunneling project (Wang et al., 2013a). The classifications of the status of existing properties were compared to the actual observations and the input parameters of the RIFs were varied to observe model output changes.

The organizational models were partly modified based on previous works. For example, the management commitment to safety module and hiring and training processes were adapted from Cooke's and Mohaghegh's models (Cooke, 2004; Mohaghegh, 2007). Other modules were constructed based on interviews with engineers and managers (Yu et al., 2014). In addition, three eminent safety scholars with tunneling experience reviewed the whole model structure to report upon any major discrepancy between the model and reality.

\section{- $\quad$ Schedule performance}

Schedule performance is presented in Figure 14. The stairs diagram indicates the tunneling project's progress while the line shows the average daily advance speed. Although completed on time, the average tunneling advance speed varied significantly between a relatively low initial speed which increased significantly during the last month. 
- $\quad$ Financial performance

Figure 15 shows the project's financial status relative to accident caused financial loss. Most simulated accidents are 'insignificant' or 'considerable', except for two 'serious' accidents on days 64 and 77. The difference between the initial value and the final financial value indicates total profit. Due to accidents, profits dramatically reduced to $1.46 \%$, from an expected $10.11 \%$ to $8.65 \%$.

\section{- Safety performance}

The variance of safety performance indicators (i.e. risk level and accident severity), are presented in Figure 16. The overall risk level is labeled 'negligible' for 45 days and 'acceptable' for 42 days respectively. The 'unwanted' risk level appears at days 64, 65 and 76, with two 'serious' accidents that occurred. Notably, the accidents and high risk level appears more frequently in the second half of the construction period, implying a downward safety performance.

To better present risk migration measures employed, the spatio-temporal dynamics of tunneling-induced damage risks to ground surface, adjacent structures and pipelines are shown in Figure 17. The abscissa stands for time and the ordinate indicates the section of excavation face. The risks of tunneling-induced damage to ground surface, adjacent structures and pipelines are represented by circle, triangular and square markers, with different colors indicating the risk levels (i.e. acceptable: yellow; unwanted: orange, unacceptable: red). For example, the excavation face reaches Section $256.64 \mathrm{~m}$ at day 20 and the building located at section $250 \mathrm{~m}$ (i.e. S4 in Figure 3), namely $6.64 \mathrm{~m}$ behind the excavation face, and is assessed as being at an 'acceptable' risk level. Similarly, the pipeline located at section 820m (i.e. P3 in Figure 3) reaches high risk level as the shield machine approaches and recedes from section $808.14 \mathrm{~m}$ to $848.52 \mathrm{~m}$, and the risks of tunneling-induced damage to adjacent structure, pipeline and ground surface reaches 'acceptable' simultaneously at day 77, which leads the tunneling project to the 'unwanted' risk level for 3 days.

\section{DISCUSSION}

The simulation results illustrate that management commitment to safety varies during 
construction works (refer to Figure 18). As risk mitigation activities were initially implemented (e.g. improve safety training and low backlog of safety tasks - Figures 19 and 20), the assessed risk level was low and no accidents occurred, resulting in a consequential shift of management focus to production. Production continued to increase until low-cost accidents (i.e. insignificant or considerable accidents) occurred, which can lead to improvement in protection. However, an increased focus on protection may reduce the apparent absence of accidents and risks, triggering a decline in safety awareness. Consequently, the level of protection is then gradually eroded until another accident occurred or high risks are perceived. These dynamics are captured in Figure 19 as the management commitment to safety fluctuated over time; this phenomenon can be understood as the archetypes of decreasing safety consciousness and complacency (Marais et al., 2006). Safety awareness can be reinforced by increasing the number of incidents and the system safety is improved by efforts to reduce incidents. But the absence of incidents renders the system mute and may create complacency. As production pressures increase, adherence to protection activities that seem draconian and unnecessarily costly may erode, eventually elevating accident risk.

As the analysis demonstrates, previously low-cost accidents can engender increasing production pressure. In addition, efforts to reduce accidents gradually decreased safety awareness as the management commitment declined after day 40. Although several insignificant or considerable accidents occurred around day 50, the level of management commitment increased slowly due to the time lag of management commitment change and high production pressure. Unwanted risk levels and a serious accident were observed around day 65 as the shield machine happened to underpass a pipeline (P3 in Figure 3). This is in line with Reason's Swiss cheese model (1997), whereby the latent failures, occurs at the managerial and organizational level, and combine adversely with local triggering events that cause an organizational accident. In this case, the production pressure continually forced the system to move outside the safety margin where serious accidents were actually waiting to release (Rasmussen, 1997). The unexpected incidents triggered a vicious cycle, which occurred after the remedies and a stronger management focus on production was encouraged due to the demanding schedule. Consequently, a second serious 
accident occurred at day 78 .

Detailed investigation of the two accidents also found a high backlog of safety tasks prior to the events (cf. Figure 21). This is better understood as the archetype of side-effect of safety fixes (Marais et al., 2006). Once high risk is perceived or an accident occurs, the natural act is to fix the symptoms rather than address root causes. The analysis implies that a project organization has to continually foster a good safety culture that maintains a high level of safety awareness. High risks and major accidents are preceded by incidents such as low-cost accidents or perceived low level risks (Goh et al., 2012). The possible solution is to adjust the production goal so that the project organization can invest more in protection to ensure a sustainable safety state where skilled workers can implement counter-measures without heavy time pressures. Moreover, as the absence of incidents may decrease a project's organizational safety awareness, the leading indicators of safety performance should be monitored and the threshold of low risk should be enhanced to remind the organization that risk is not negligible.

\section{CONCLUSIONS}

Investigation of recent large-scale accidents during tunnel construction continued to cite organizational management as a major contributory factor. Tunneling projects are socio-technical systems where their performance is determined by the interaction between the organizational processes and technical systems. Although both organizational and technical dimensions should be incorporated into safety risk analysis, limited effort has been made to integrate these two parts to investigate a safety system's behavior. This is perhaps due to a highly complex and loosely coupled tunnel construction process which requires dynamic modeling techniques applied to different modules from a systems perspective. This study developed a systemic safety risk model that takes into account this challenge.

A conceptual framework proposed depicted the relationships between different organizational goals, and examined how organizational factors interact with technical risks. The aim was to obtain a broader picture of the etiology of a system breakdown so that the interaction of organizational management and technical failures within the 'production and protection' 
constraint could be addressed. Within the framework, a model called 'ORDO' was established by embedding the technical models into the organizational processes in the SD environments. A large amount of diverse data was collected from a metro tunnel construction case provided an opportunity to run simulations. Results demonstrated the dynamics of system migration toward high risk under the pressure of production. The analysis of the mechanisms of risk dynamics implied that the possible solutions to resist safety system drift from a 'safety zone' to a 'hazardous state.' In order to establish a robust safety culture, construction managers and staff must continue to champion the philosophy of safety first and monitor safety performance indicators. This will include learning lessons and feeding them back into management practices, particularly in the face of increasing production pressure. In certain circumstances, the production goal has to be compromised to maintain system safety.

The example application sought to explore the feasibility of the proposed hybrid methodology rather than performing a comprehensive and realistic numerical estimation of the tunneling risks. By using this approach, the dynamic influence of organizational factors on technical system safety risk and its feedback is presented. Future work is however required to: i) investigate the inter-organizational relationships between stakeholders (owner, contractor, supervisors etc.) and how these impact upon tunneling performance; and ii) expand the research scope to examine the effects of different managerial factors on safety performance. Manipulation of these factors will allow output changes to be recorded (as a first step towards improving model applicability) but such work requires an abundance of data to support quantitative modelling. 


\section{REFERENCES}

Aksorn T, Hadikusumo BHW. Critical success factors influencing safety program performance in Thai construction projects. Saf Sci 2008; 46: 709-27.

Apostolakis GE. How useful is quantitative risk assessment? Risk Anal 2004; 24: 515-20.

Argyris C, Schon D. Organizational learning II: Theory, method and practice. Reading, MA: Addison-Wesley; 1996.

Atak A, Kingma S. Safety culture in an aircraft maintenance organisation: A view from the inside. Saf Sci 2011; 49: 268-78.

Bellamy LJ, Geyer TAW, Wilkinson J. Development of a functional model which integrates human factors, safety management systems and wider organisational issues. Saf Sci 2008; 46: 461-92.

Bier VM. Challenges to the acceptance of probabilistic risk analysis. Risk Anal 1999; 19: $703-10$.

Brooks B. The natural selection of organizational and safety culture within a small to medium sized enterprise (SME). J Safety Res 2008; 39: 73-85.

Cárdenas IC, Al-jibouri SSH, Halman JIM, van Tol F. Capturing and integrating knowledge for managing risks in tunnel works. Risk Anal 2013; 33: 92-108.

Carroll J, Rudolph J, Hatakenaka S. Organizational learning from experience in high-hazard industries: problem investigations as off-line reflective practice. Cambridge, MA: MIT Sloan School of Management; 2002.

Carrillo P, Chinowsky P. Exploiting knowledge management: The engineering and construction perspective. J Manage Eng 2006; 22: 2-10.

Chen C-Y, Wu G-S, Chuang K-J, Ma C-M. A comparative analysis of the factors affecting the implementation of occupational health and safety management systems in the printed circuit board industry in Taiwan. J Loss Prevent Proc 2009; 22: 210-5.

Choudhry RM, Fang D, Mohamed S. Developing a Model of Construction Safety Culture. J Manage Eng 2007a; 23: 207-12.

Choudhry RM, Fang D, Mohamed S. The nature of safety culture: A survey of the state-of-the-art. Saf Sci 2007b; 45: 993-1012. 
Clough RH, Sears CA, Sears SK. Construction Project Management. 4th ed. New York: Wiley; 2000 .

Cooke DL.The dynamics and control of operational risk. PhD. thesis, University of Calgary, 2004.

Cooper MD. Towards a model of safety culture. Saf Sci 2000; 36, 111-36.

Cowing MM, Paté-Cornell ME, Glynn PW. Dynamic modeling of the tradeoff between productivity and safety in critical engineering systems. Reliab Eng Syst Safe 2004; 86: 269-84.

Cox S, Flin R. Safety culture: Philosopher's stone or man of straw? Work Stress 1998; 12: $189-201$

Dağdeviren M, Yüksel İ. Developing a fuzzy analytic hierarchy process (AHP) model for behavior-based safety management. Inform Sciences 2008; 178: 1717-33.

Dekker S. The field guide to understanding human error. Farnham, UK: Ashgate Publishing; 2006.

Dekker S. Drift into failure: From hunting broken components to understanding complex systems. Farnham, UK: Ashgate Publishing; 2011.

Díaz-Cabrera D, Hernández-Fernaud E, Isla-Díaz R. An evaluation of a new instrument to measure organisational safety culture values and practices. Accident Anal Prev 2007; 39: $1202-11$.

Ding L, Wang F, Luo H, Yu M, Wu X. Feedforward analysis for shield-ground system. J Comput Civil Eng 2013; 27: 231-42.

Dulac N, Leveson N, Zipkin D, Friedenthal S, Cutcher-Gershenfeld J, Carroll J, Barrett B. Using system dynamics for safety and risk management in complex engineering systems. In: Proceedings of the 2005 Winter Simulation Conference, Orlando, Florida, USA, 2005. p. $1311-20$.

Dyreborg J. The causal relation between lead and lag indicators. Saf Sci 2009; 47: 474-5.

Edwards CJ. Aircraft operators have built a generic hazard model for use in developing safety cases. ICAO-J 2000; 55: 12-4.

Edwards, D.J., Harris, F.C. and McCaffer, R. (2003) Management of Off-highway Plant and 
Equipment, E and FN Spon, London.

Eskesen SD, Tengborg P, Kampmann J, Veicherts TH. Guidelines for tunnelling risk management: International Tunnelling Association, Working Group No. 2. Tunn Undergr Sp Tech 2004; 19: 217-37.

Fang DP, Xie F, Huang XY, Li H. Factor analysis-based studies on construction workplace safety management in China. Int J Proj Manage 2004; 22: 43-9.

Fernández-Muñiz B, Montes-Peón JM, Vázquez-Ordás CJ. Safety culture: Analysis of the causal relationships between its key dimensions. J Safety Res 2007a; 38: 627-41.

Fernández-Muñiz B, Montes-Peón JM, Vázquez-Ordás CJ. Safety management system: Development and validation of a multidimensional scale. J Loss Prevent Proc, 2007b; 20: $52-68$.

Flyvbjerg B, Holm MS, Buhl SL. Underestimating costs in public works projects, Error or Lie. J Am Plann Assoc 2002; 68: 279-95.

Goh YM, Brown H, Spickett J. Applying systems thinking concepts in the analysis of major incidents and safety culture. Saf Sci 2010; 48: 302-9.

Goh YM, Love PED, Brown H, Spickett J. Organizational accidents: A systemic model of production versus protection. J Manage Stud 2012a; 49: 52-76.

Goh YM, Love PED, Stagbouer G, Annesley C. Dynamics of safety performance and culture: A group model building approach. Accident Anal Prev 2012b; 48: 118-25.

Goldstein J. Editorial: Meso scale social dynamics and advances in complexity science. E:CO Issue, 2010; 12: pp.v-vii.

Grote G. Safety management in different high-risk domains - All the same? Saf Sci 2012; 50: 1983-92.

Guldenmund FW. The nature of safety culture: A review of theory and research. Saf Sci 2000; 34: $215-57$.

Hale AR, Heming BHJ, Carthey J, Kirwan B. Modelling of safety management systems. Saf Sci 1997; 26: 121-40.

Hinze J, Thurman S, Wehle A. Leading indicators of construction safety performance. Saf Sci, 2013; 51: $23-8$. 
Hong E, Lee I, Shin H, Nam S, Kong J. Quantitative risk evaluation based on event tree analysis technique: Application to the design of shield TBM. Tunn Undergr Sp Tech, 2009; 24: 269-77.

Howell GA, Ballard G, Abdelhamid T, Mitropoulos P. Rethinking safety: learning to work near the edge. In: Proceedings of Construction Research Congress: Wind of Change: Integration and Innovation, Honolulu, Hawaii, USA, 2003. p. 1-8.

Hsu Y-L, Li W-C, Chen K-W. Structuring critical success factors of airline safety management system using a hybrid model. Transport Res E-Log 2010; 46: 222-35.

Ismail Z, Doostdar S, Harun Z. Factors influencing the implementation of a safety management system for construction sites. Saf Sci 2012; 50: 418-23.

Kaplan S, Garrick BJ. On the quantitative definition of risk. Risk Anal 1981; 1: 11-27.

Kasper T, Meschke G. A 3D finite element simulation model for TBM tunnelling in soft ground. Int J Numer Anal Meth Geomech 2004; 28: 1441-60.

Kazaras K, Kirytopoulos K, Rentizelas A. Introducing the STAMP method in road tunnel safety assessment. Saf Sci 2012; 50: 1806-17.

Kennedy R, Kirwan B. Development of a Hazard and Operability-based method for identifying safety management vulnerabilities in high risk systems. Saf Sci 1998; 30: 249-74.

Kongsvik T, Almklov P, Fenstad J. Organisational safety indicators: Some conceptual considerations and a supplementary qualitative approach. Saf Sci 2010; 48: 1402-11.

Kyriakidis M, Hirsch R, Majumdar A. Metro railway safety: An analysis of accident precursors. Saf Sci 2012; 50: 1535-48.

Le Coze J. Are organisations too complex to be integrated in technical risk assessment and current safety auditing? Saf Sci 2005; 43: 613-38.

Le Coze J. Outlines of a sensitising model for industrial safety assessment. Saf Sci 2013; 51: $187-201$.

Leveson N, Daouk M, Dulac N, Marais K. Applying STAMP in accident analysis. In: Proceedings of the Second Workshop Investigation and Reporting of Accidents. 2003.

Leveson N. A new accident model for engineering safer systems. Saf Sci 2004; 42: 237-70.

Leveson N. Applying systems thinking to analyze and learn from events. Saf Sci 2011; 49: 
$55-64$.

Leveson N, Dulac N, Marais K, Carroll J. Moving beyond normal accidents and high reliability organizations: a systems approach to safety in complex systems. Organ Stud 2009; 30: $91-113$.

Lofquist EA. The art of measuring nothing: The paradox of measuring safety in a changing civil aviation industry using traditional safety metrics. Saf Sci 2010; 48: 1520-9.

Love PED, Holt GD, Shen LY, Li H, Irani Z. Using systems dynamics to better understand change and rework in construction project management systems. Int J Proj Manage 2002; 20: 425-36.

Love PED, Irani Z, Edwards DJ. A rework reduction model for construction projects. IEEE T Eng Manage 2004; 51: 426-40.

Love PED, Edwards DJ. Curbing rework in offshore projects: Systemic classification of risks with dialogue and narratives. Struct Infrastruct Eng 2013; 9: 1118-35.

Love PED, Wang X, Sing C-P, Irani Z, Thwala D. Overruns in transportation infrastructure projects. Struct Infrastruct Eng 2014; 10: 141-59.

Maidl B, Herrenknecht M, Maidl U, Wehrmeyer G. Mechanised shield tunnelling. 2nd ed. Berlin, Germany: Ernst \& Sohn; 2012.

Mandal S, Maiti J. Risk analysis using FMEA: Fuzzy similarity value and possibility theory based approach. Expert Syst Appl 2014; 41: 3527-37.

Marais K, Dulac N, Leveson N. Beyond normal accidents and high reliability organizations: the need for an alternative approach to safety in complex systems. In: Engineering Systems Division Symposium, MIT, Cambridge, MA, 2004.

Marais K, Saleh JH, Leveson NG. Archetypes for organizational safety. Saf Sci 2006; 44: $565-82$.

Marais K, Saleh JH. Conceptualizing and communicating organizational risk dynamics in the thoroughness-efficiency space. Reliab Eng Syst Safe 2008; 93: 1710-9.

Marhavilas PK, Koulouriotis D, Gemeni V. Risk analysis and assessment methodologies in the work sites: On a review, classification and comparative study of the scientific literature of the period 2000-2009. J Loss Prevent Proc 2011; 24: 477-523. 
McDonald N, Corrigan S, Daly C, Cromie S. Safety management systems and safety culture in aircraft maintenance organisations. Saf Sci 2000; 34: 151-76.

Mearns K, Whitaker SM, Flin R. Safety climate, safety management practice and safety performance in offshore environments. Saf Sci 2003; 41: 641-80.

Mitropoulos P, Abdelhamid TS, Howell GA. Systems model of construction accident causation. J Constr Eng M 2005; 131: 816-25.

Mohaghegh Z. On the theoretical foundations and principles of organizational safety risk analysis. PhD. thesis, University of Maryland, College Park. 2007.

Mohaghegh Z, Mosleh A. Incorporating organizational factors into probabilistic risk assessment of complex socio-technical systems: Principles and theoretical foundations. Saf Sci 2009; 47: 1139-58.

Mohaghegh Z, Kazemi R, Mosleh A. Incorporating organizational factors into Probabilistic Risk Assessment (PRA) of complex socio-technical systems: A hybrid technique formalization. Reliab Eng Syst Safe 2009; 94: 1000-18.

Mohamed S. Scorecard approach to benchmarking organizational safety culture in construction. J Constr Eng M 2003; 129: 80-8.

Nývlt O, Prívara S, Ferkl L. Probabilistic risk assessment of highway tunnels. Tunn Undergr Sp Tech 2011; 26: 71-82.

Ouyang M, Hong L, Yu M, Fei Q. STAMP-based analysis on the railway accident and accident spreading: taking the China-Jiaoji railway accident for example. Saf Sci 2010; 48: 544-55.

O'toole M. The relationship between employees' perceptions of safety and organizational culture. J Safety Res 2002; 33: 231-43.

Parker D, Lawrie M, Hudson P. A framework for understanding the development of organisational safety culture. Saf Sci 2006; 44: 551-62.

Pasquini A, Pozzi S, Save L. A critical view of severity classification in risk assessment methods. Reliab Eng Syst Safe 2011; 96: 53-63.

Paté-Cornell ME, Murphy DM. Human and management factors in probabilistic risk analysis: the SAM approach and observations from recent applications. Reliab Eng Syst Safe 1996; 53: $115-26$. 
Peck RB. Deep excavation and tunnelling in soft ground. In: Proceedings of the 7 th Int. Conf. Soil Mechanics and Foundation Engineering, Univ. Nacional Autonoma de Mexico Instituto de Ingenira, Mexico City, 1969. p. 225-90.

Pérez-Marín M, Rodríguez-Toral MA. HAZOP-Local approach in the Mexican oil \& gas industry. J Loss Prevent Proc 2013; 26: 936-40.

Perrow C. Normal accidents-Living with high-risk technologies. New York: Basic Books; 1984.

Petersen D. Safety management 2000: Our strengths \& weaknesses. Prof Safety 2000; 1: 16-9.

Pidgeon N, O'Leary M. Man-made disasters: why technology and organizations (sometimes) fail. Saf Sci 2000; 34: 15-30.

Qu X, Meng Q, Yuanita V, Wong YH. Design and implementation of a quantitative risk assessment software tool for Singapore road tunnels. Expert Syst Appl 2011; 38: $13827-34$.

Ramli AA, Watada J, Pedrycz W. Possibilistic regression analysis of influential factors for occupational health and safety management systems. Saf Sci 2011; 49: 1110-7.

Reiman T, Pietikäinen E. Leading indicators of system safety-Monitoring and driving the organizational safety potential. Saf Sci 2012; 50: 1993-2000.

Rasmussen J, Nixon P, Warner F. Human error and the problem of causality in analysis of accidents. Philos T R Soc B 1990; 327: 449-62.

Rasmussen J. Risk management in a dynamic society: A modelling problem. Saf Sci 1997; 27: $183-213$.

Reason J. Human error. New York: Cambridge University Press; 1990.

Reason J. Managing the Risks of Organizational Accidents. Bookfield, VT, USA: Ashgate, 1997.

Reason J. Achieving a safe culture: Theory and practice. Work Stress 1998; 12: 293-306.

Ren J, Jenkinson I, Wang J, Xu DL, Yang JB. A methodology to model causal relationships on offshore safety assessment focusing on human and organizational factors. J Safety Res 2008; 39: 87-100.

Rodrigues A, Bowers J. The role of system dynamics in project management. Int J Proj Manage 1996; 14: 213-20.

Saleh JH, Marais KB, Bakolas E, Cowlagi RV. Highlights from the literature on accident 
causation and system safety: Review of major ideas, recent contributions, and challenges. Reliab Eng Syst Safe 2010; 95: 1105-16.

Salmon PM, Cornelissen M, Trotter MJ. Systems-based accident analysis methods: A comparison of Accimap, HFACS, and STAMP. Saf Sci 2012; 50: 1158-70.

Santos-Reyes J, Beard AN. Assessing safety management systems. J Loss Prevent Proc 2002; 15 : $77-95$.

Schmolck A, Everson R. Smooth relevance vector machine: a smoothness prior extension of the RVM. Mach Learn 2007; 68: 107-35.

Singpurwalla ND, Booker JM. Membership functions and probability measures of fuzzy sets. J Am Stat Assoc 2004; 99: 867-77.

Sorensen JN. Safety culture: A survey of the state-of-the-art. Reliab Eng Syst Safe 2002; 76: $189-204$.

Sousa RL. Risk Analysis for Tunneling Projects. PhD. thesis, Massachusetts Institute of Technology, 2010.

Sousa RL, Einstein HH. Risk analysis during tunnel construction using Bayesian Networks: Porto Metro case study. Tunn Undergr Sp Tech 2012; 27: 86-100.

Stäbler SG, Ewaldt JW. Simulation modeling and analysis of complex learning processes in organizations. Account, Manage Inform Tech, 1998; 8: 255-63.

Sterman J. Business dynamics: System thinking and modeling for complex world. New York: McGraw-Hill Companies; 2000.

Stroeve SH, Blom HAP, Bakker GJ. Systemic accident risk assessment in air traffic by Monte Carlo simulation. Saf Sci 2009; 47: 238-49.

Stroeve SH, Sharpanskykh A, Kirwan B. Agent-based organizational modelling for analysis of safety culture at an air navigation service provider. Reliab Eng Syst Safe 2011; 96: 515-33.

Sturk R, Olsson L, Johansson J. Risk and decision analysis for large underground projects, as applied to the Stockholm Ring Road tunnels. Tunn Undergr Sp Tech 1996; 11: 157-64.

Tam CM, Tong TKL, Chiu GCW, Fung IWH. Non-structural fuzzy decision support system for evaluation of construction safety management system. Int J Proj Manage 2002; 20: $303-13$. 
Taroun A. Towards a better modelling and assessment of construction risk: Insights from a literature review. Int J Proj Manage 2014; 32:101-15.

Teo EAL, Ling FYY. Developing a model to measure the effectiveness of safety management systems of construction sites. Build Environ 2006; 41: 1584-92.

Tipping ME. Sparse Bayesian learning and the relevance vector machine. J Mach Learn Res 2001; 1: 211-44.

Turner BA, Pidgeon NF, Man-made Disasters. 2nd ed. London: Butterworth- Heinemann; 1997.

Wanberg J, Harper C, Hallowell M, Rajendran S. Relationships between construction safety and quality performance. J Constr Eng M 2013; 139: 10p.

Wang F, Ding LY, Luo HB, Love PED. Probabilistic risk assessment of tunneling-induced damage to existing properties. Expert Syst Appl 2013a; 41: 951-61.

Wang F, Gou B, Qin Y. Modeling tunneling-induced ground surface settlement development using a wavelet smooth relevance vector machine. Comput Geotech 2013b; 54: 125-32.

Weick KE. Organizational culture as a source of high reliability. Calif Manage Rev 1991; 29: $112-27$.

Westrum R. Culture with requisite imagination. In: Wise JA, Hopkin VD, Stager P Editors. Verification and validation of complex systems: Human factors issues. Berlin: Springer-Verlag; 1992, p. 401-16.

Wiegmann DA, Zhang H, Von Thaden TL, Sharma G, Mitchell AA. A synthesis of safety culture and safety climate research. Technical Report ARL-02-03/FAA-02-2, University of Illinois Aviation Research Lab, Savoy, IL, 2002.

Yu QZ, Ding LY, Zhou C, Luo HB. Analysis of factors influencing safety management for metro construction in China. Accident Anal Prev 2014; 68: 131-8.

Zohar D. Safety climate in industrial organizations: Theoretical and applied implications. J Appl Psychol 1980; 65: 96-102.

Zou PXW. Fostering a strong construction safety culture. Leadership Manage Eng 2011; 11: $11-22$.

Øien K. A framework for the establishment of organizational risk indicators. Reliab Eng Syst Safe 2001; 74: 147-67. 
Figure 1 - A framework for risk modeling on tunneling projects.

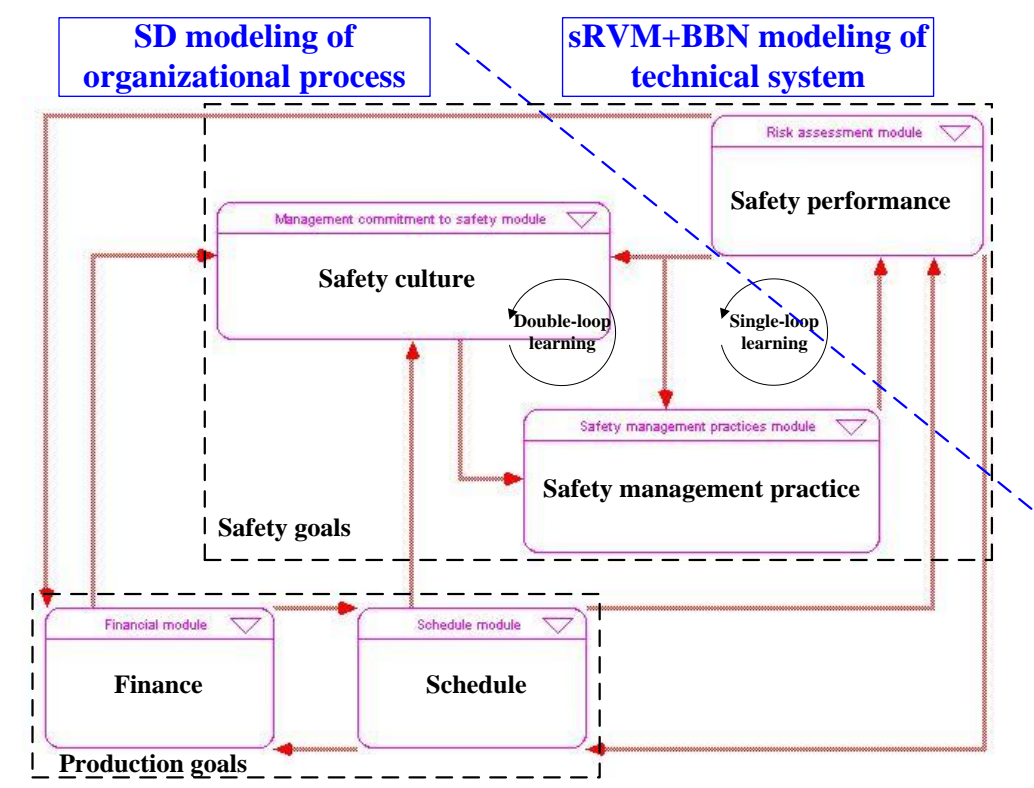


Table 1 - Examples of the good safety management practices.

\begin{tabular}{|c|c|c|c|c|c|}
\hline Authors & Major components/factors & $\begin{array}{l}\text { Total No. of } \\
\text { Components }\end{array}$ & Domain & Country & Research method* \\
\hline Tam et al. (2002) & $\begin{array}{l}\text { Safety audit scheme, Safety training, Competency of supervision, Management } \\
\text { involvement, Safety promotion }\end{array}$ & 7 & Construction & Hong Kong & NSFDSS \\
\hline Fang et al. (2004) & $\begin{array}{l}\text { Safety inspection, Safety meeting, Safety regulation enforcement, Safety } \\
\text { education, Safety communication }\end{array}$ & 11 & Construction & China & FA \\
\hline Teo and Ling (2006) & Personnel factor, Incentive factor, Process factor, Policy factor & 4 & Construction & Singapore & $\mathrm{AHP}+\mathrm{FA}$ \\
\hline $\begin{array}{l}\text { Fernández-Muñiz et al. } \\
\text { (2007b) }\end{array}$ & Internal control, Communication, Training, Preventive planning, Incentives & 8 & Multiple & Spain & $\begin{array}{l}\text { exploratory/ } \\
\text { confirmatory FA }\end{array}$ \\
\hline $\begin{array}{l}\text { Dağdeviren and Yüksel } \\
\text { (2008) }\end{array}$ & Organizational factors, Personal factors, Job related factors, Environmental factors & 4 & Manufacture & Turkey & fuzzy AHP \\
\hline $\begin{array}{l}\text { Aksorn and } \\
\text { Hadikusumo (2008) }\end{array}$ & $\begin{array}{l}\text { Management support, Safety education and training, Teamwork, Clear and realistic } \\
\text { goals, Effective enforcement scheme }\end{array}$ & 16 & Construction & Thailand & FA \\
\hline Chen et al., (2009) & $\begin{array}{l}\text { Management promises and support, Plan- do-check-action continuous } \\
\text { improvement, Participation of employees, Education and training, Internal auditing } \\
\text { system }\end{array}$ & 12 & Manufacture & Taiwan & FA \\
\hline Hsu et al., (2010) & $\begin{array}{l}\text { Safety policy, Safety culture, Communication, Training, Identification and } \\
\text { maintenance of applicable regulations }\end{array}$ & 13 & Aviation & Taiwan & $\begin{array}{l}\text { hybrid } \\
\text { (GRA+DEMATEL+ } \\
\text { ANP) }\end{array}$ \\
\hline $\begin{array}{l}\text { Ramli et al., } \\
\text { (2011) }\end{array}$ & $\begin{array}{l}\text { Safety policy and program, Hazard identification and workplace assessment, Risk } \\
\text { control strategies, Training strategy, Consultation sessions }\end{array}$ & 6 & Multiple & Malaysia & possibilistic RA \\
\hline $\begin{array}{l}\text { Ismail et al., } \\
\text { (2012) }\end{array}$ & $\begin{array}{l}\text { Personal factor, Management factor, Human resource management/Incentive } \\
\text { factor, Resources factor, Relationship factor }\end{array}$ & 5 & Construction & Various & Statistics (survey) \\
\hline
\end{tabular}

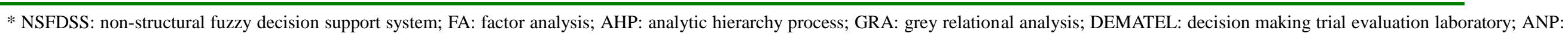
analytic network process; RA: regression analysis. 
Figure 2 - Integration of SD, BBN and SRVM, and data exchange method.

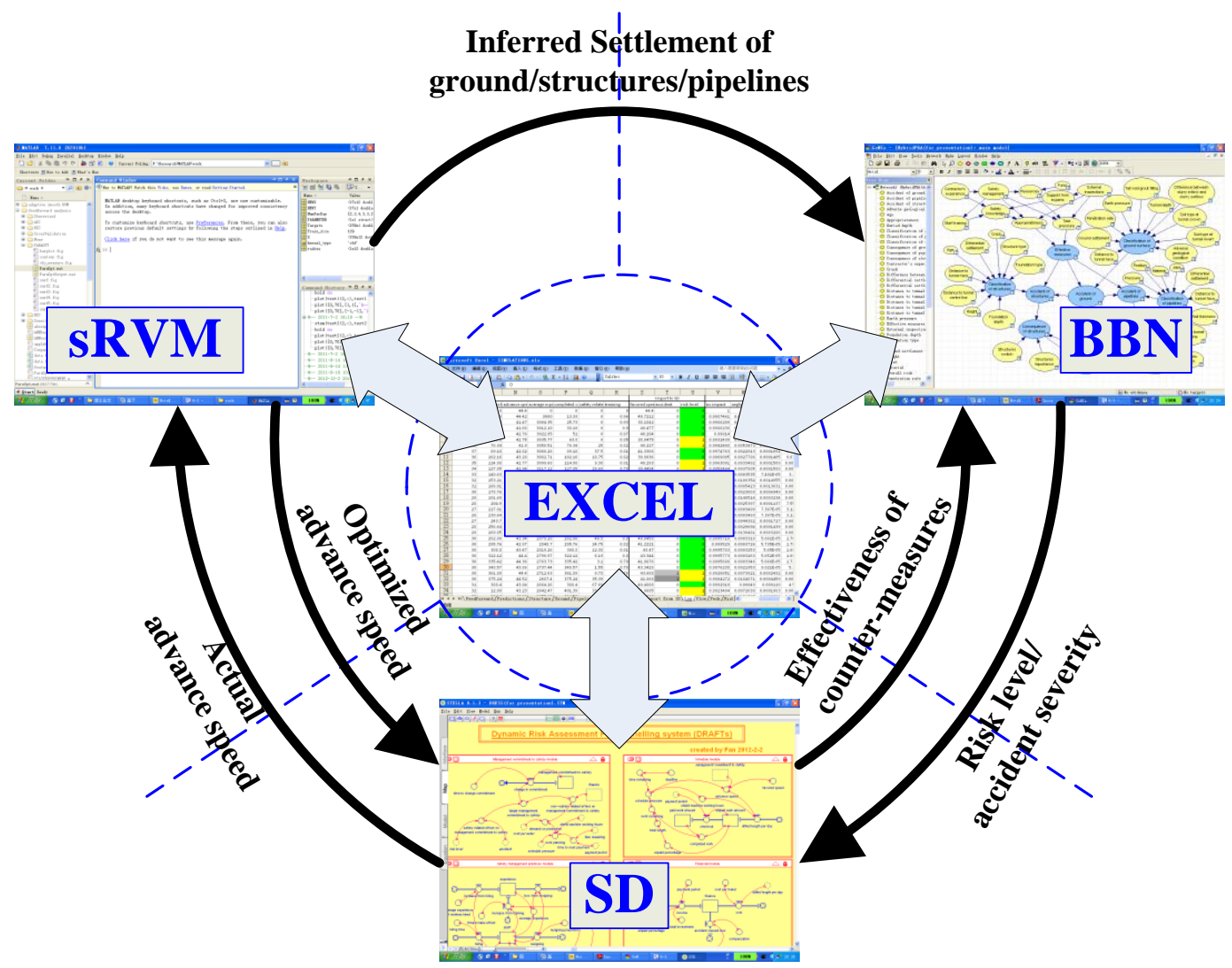


Figure 3 - Layout of the metro tunnel project.

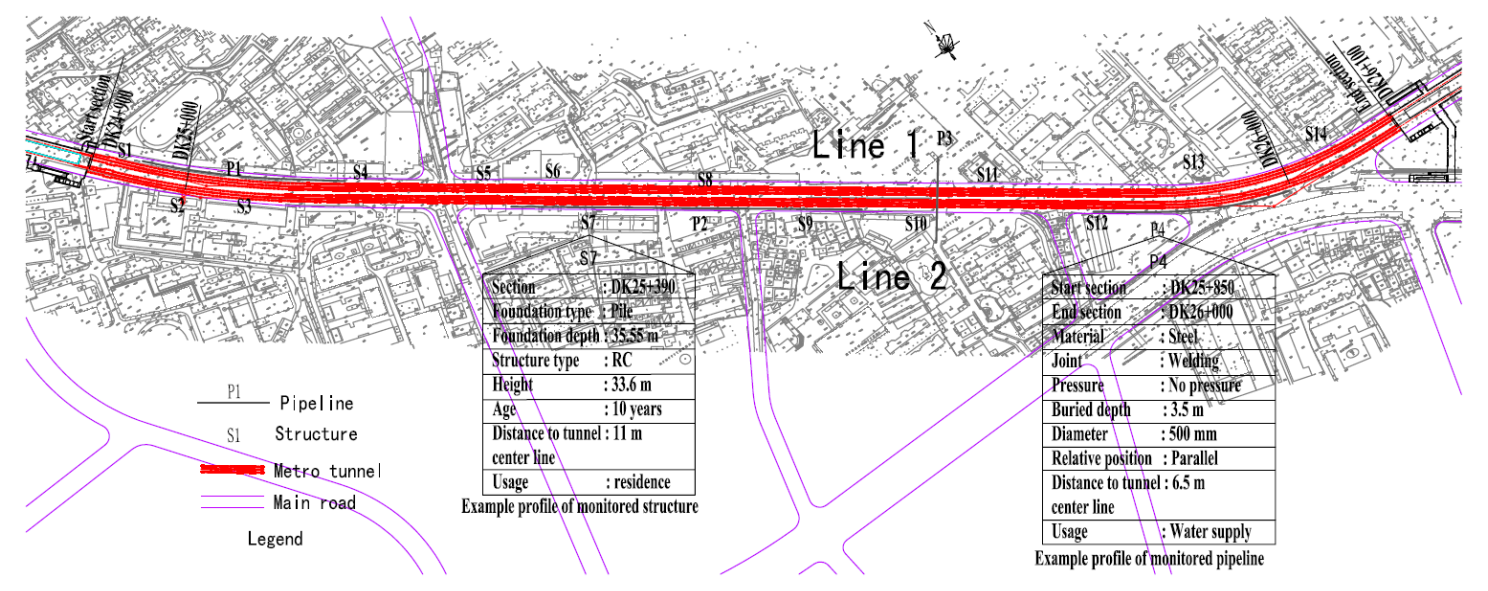


Figure 4 - Longitudinal profile of the metro tunnel project.

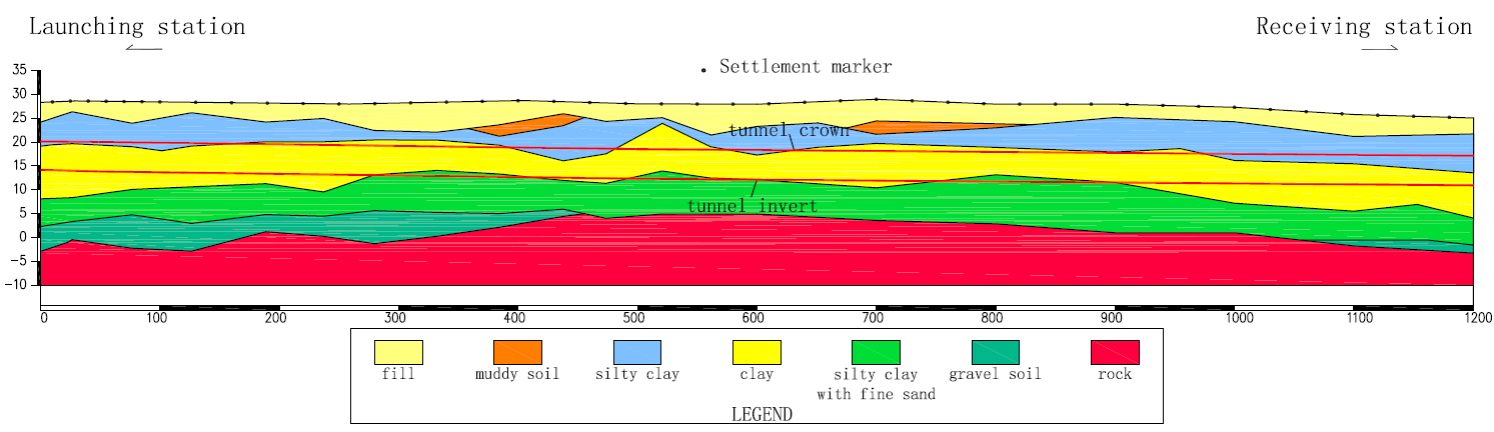


Figure 5 - Management commitment to safety module.

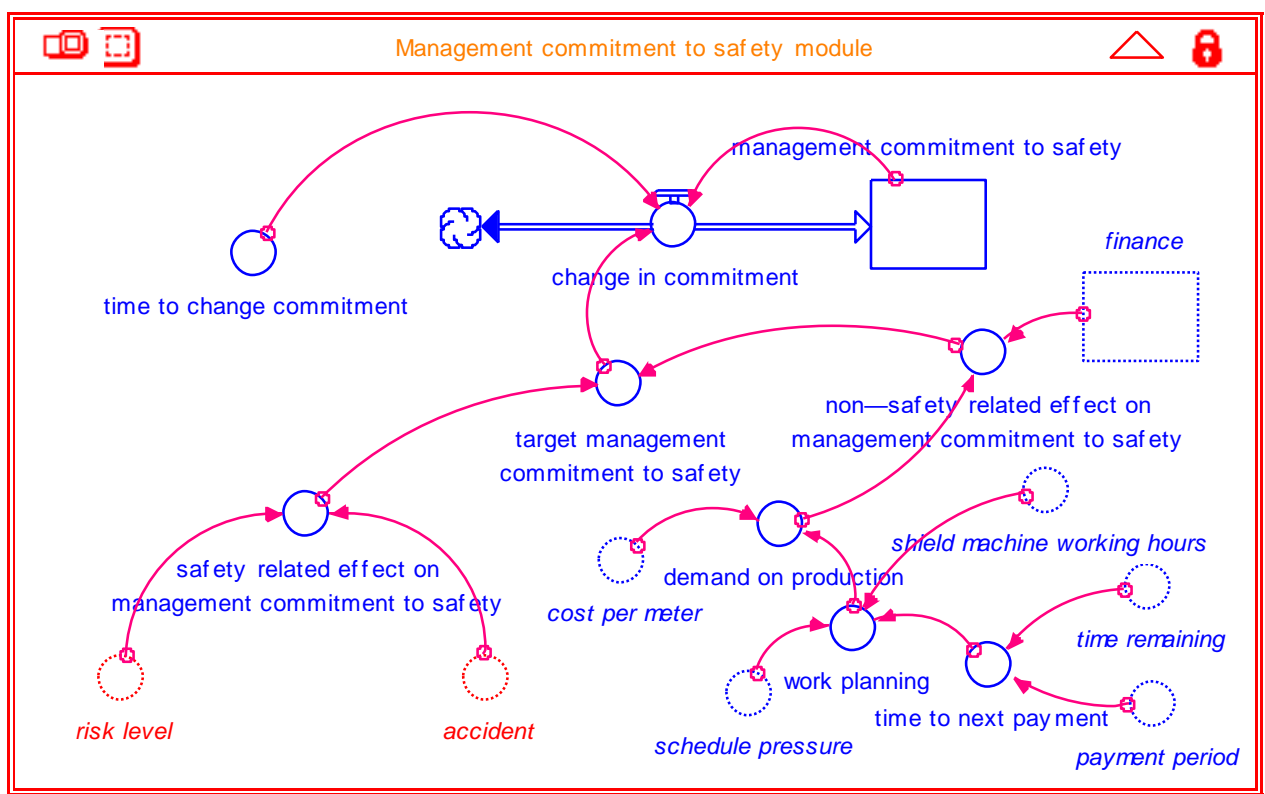


Figure 6 - Safety management practices module.

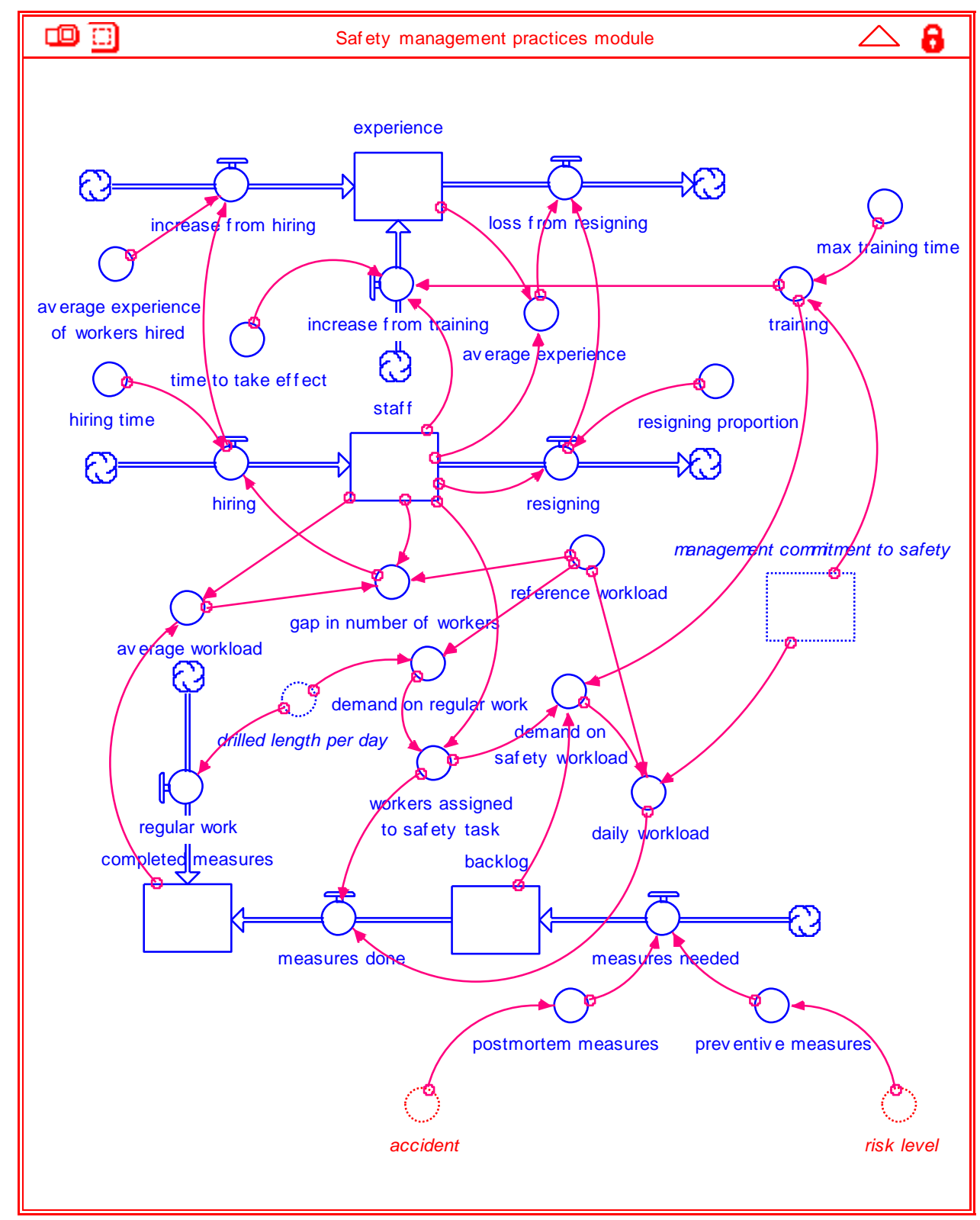


Figure 7 - Schedule module.

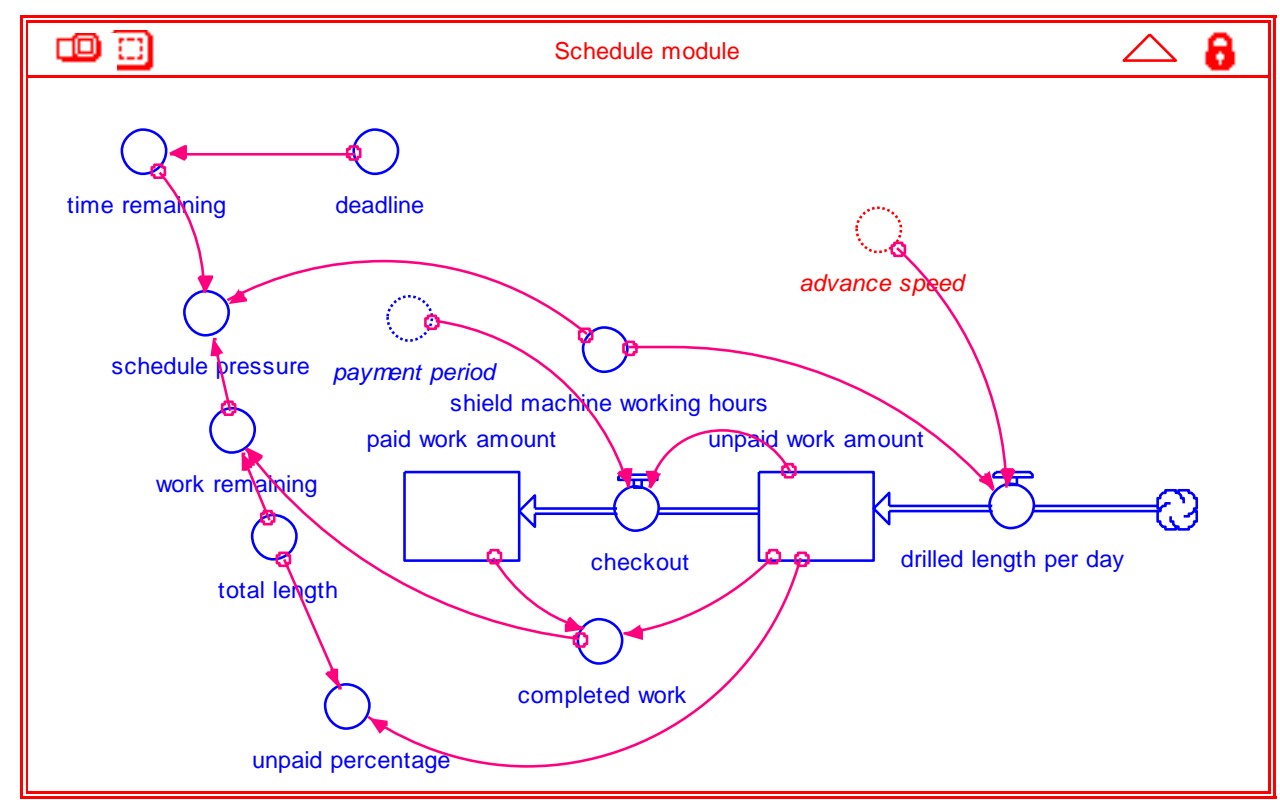


Figure 8 - Financial module.

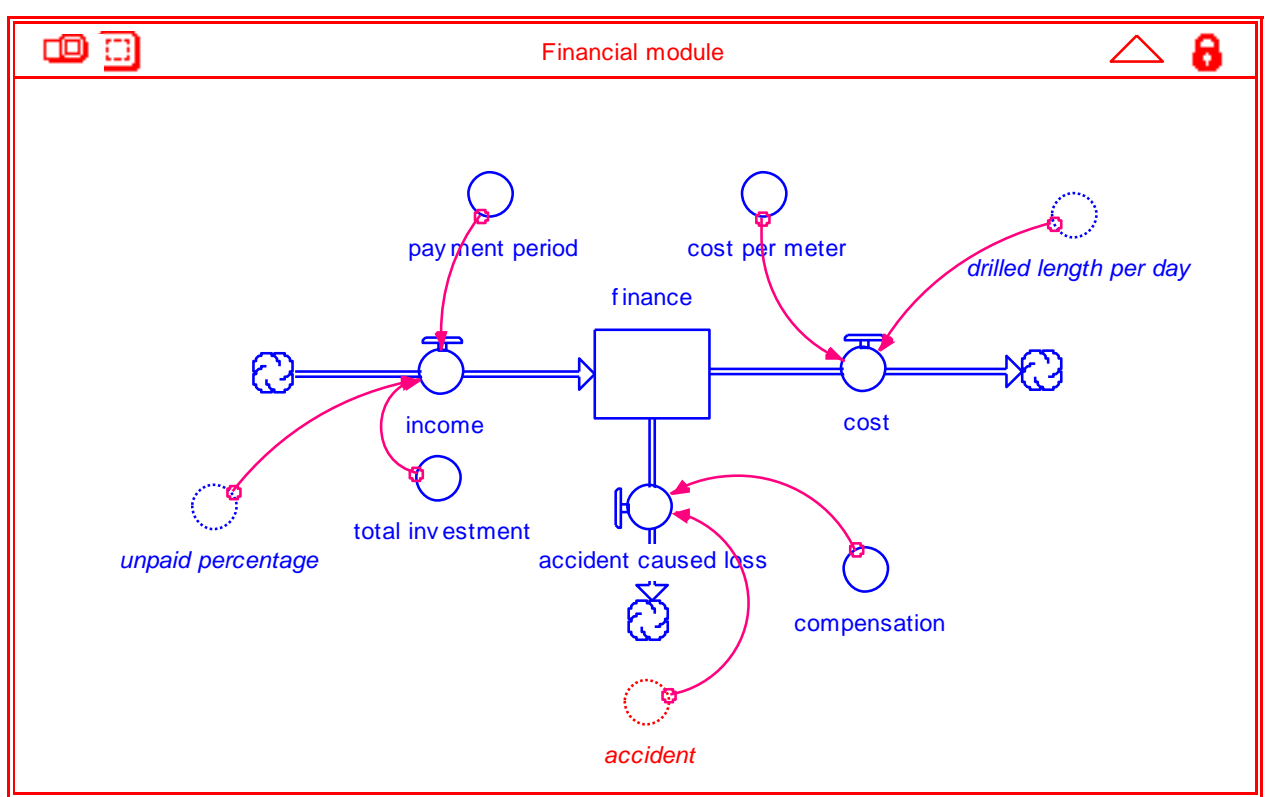


Figure 9 - Feedforward analysis for shield-ground system.

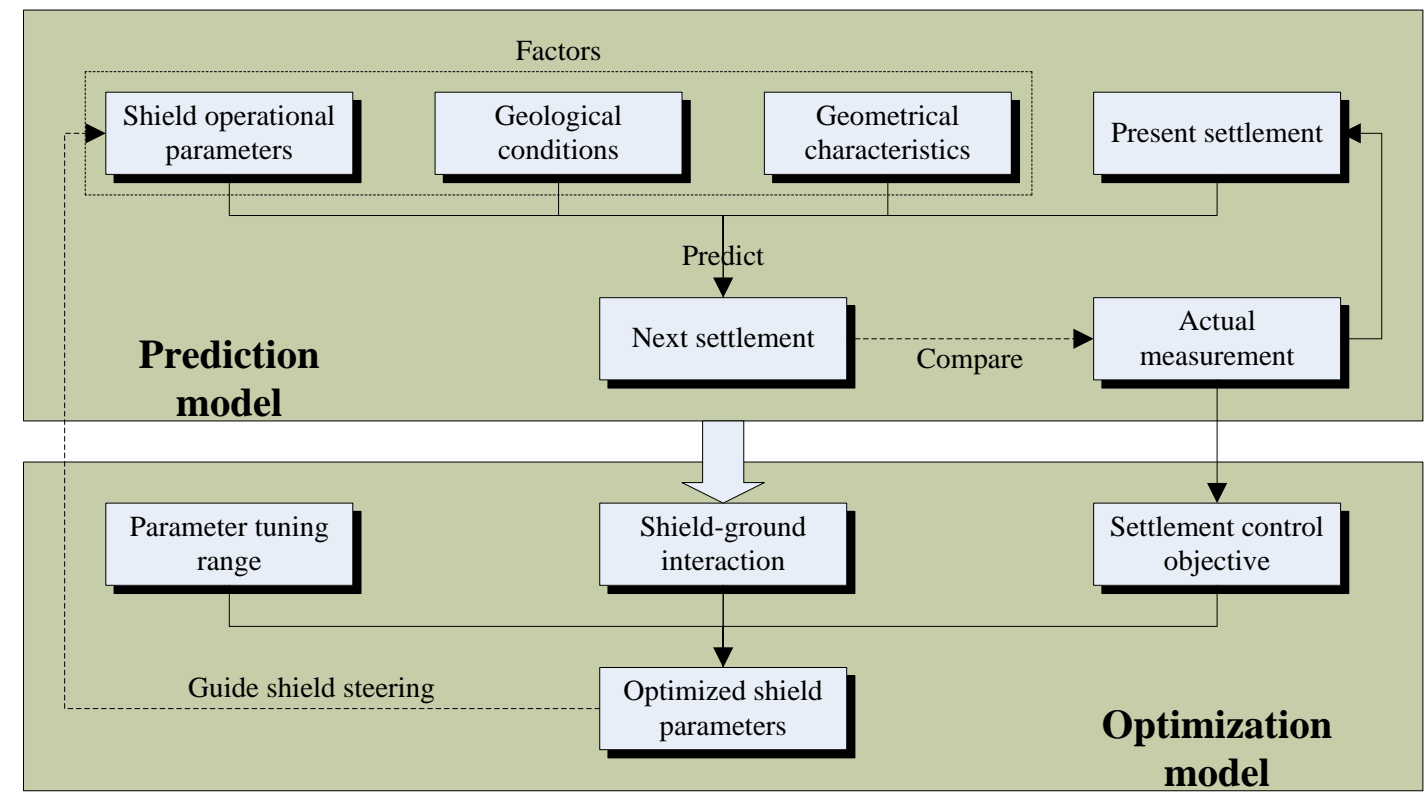


Figure 10 - Risk assessment model structure in the tunnel case.

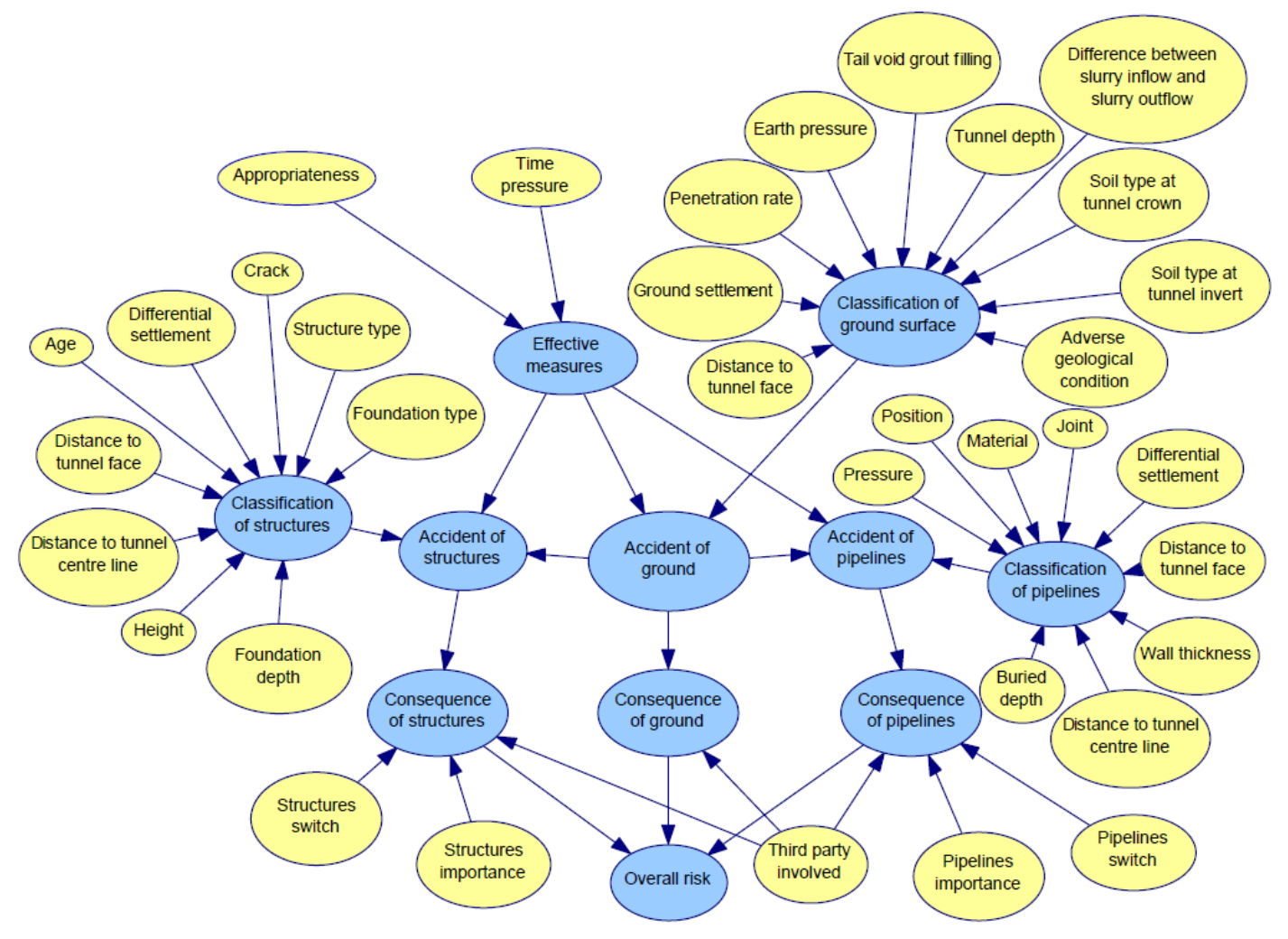


Table 2 - Frequency classification (adapted from Eskesen et al., (2004)).

\begin{tabular}{llll}
\hline Frequency class & Interval & Central value & Descriptive frequency class \\
\hline 6 & $>0.3$ & 1 & Very likely \\
5 & 0.03 to 0.3 & 0.1 & Likely \\
4 & 0.003 to 0.03 & 0.01 & Occasional \\
3 & 0.0003 to 0.003 & 0.001 & Unlikely \\
2 & 0.00003 to 0.0003 & 0.0001 & Very unlikely \\
1 & $<0.00003$ & 0.00001 & Nearly impossible \\
\hline
\end{tabular}


Table 3 - Consequence classification (adapted from Eskesen et al. (2004)).

\begin{tabular}{lllllll}
\hline $\begin{array}{l}\text { Damage to } \\
\text { third party }\end{array}$ & Disastrous & Severe & Serious & Considerable & Insignificant & No impact \\
\hline $\begin{array}{l}\text { Loss in } \\
\text { Million Euro }\end{array}$ & $>3$ & $0.3-3$ & $0.03-0.3$ & $0.003-0.03$ & $0-0.003$ & 0 \\
\hline
\end{tabular}


Figure 11 - Risk matrix in the tunnel case (adapted from Eskesen et al., (2004)).

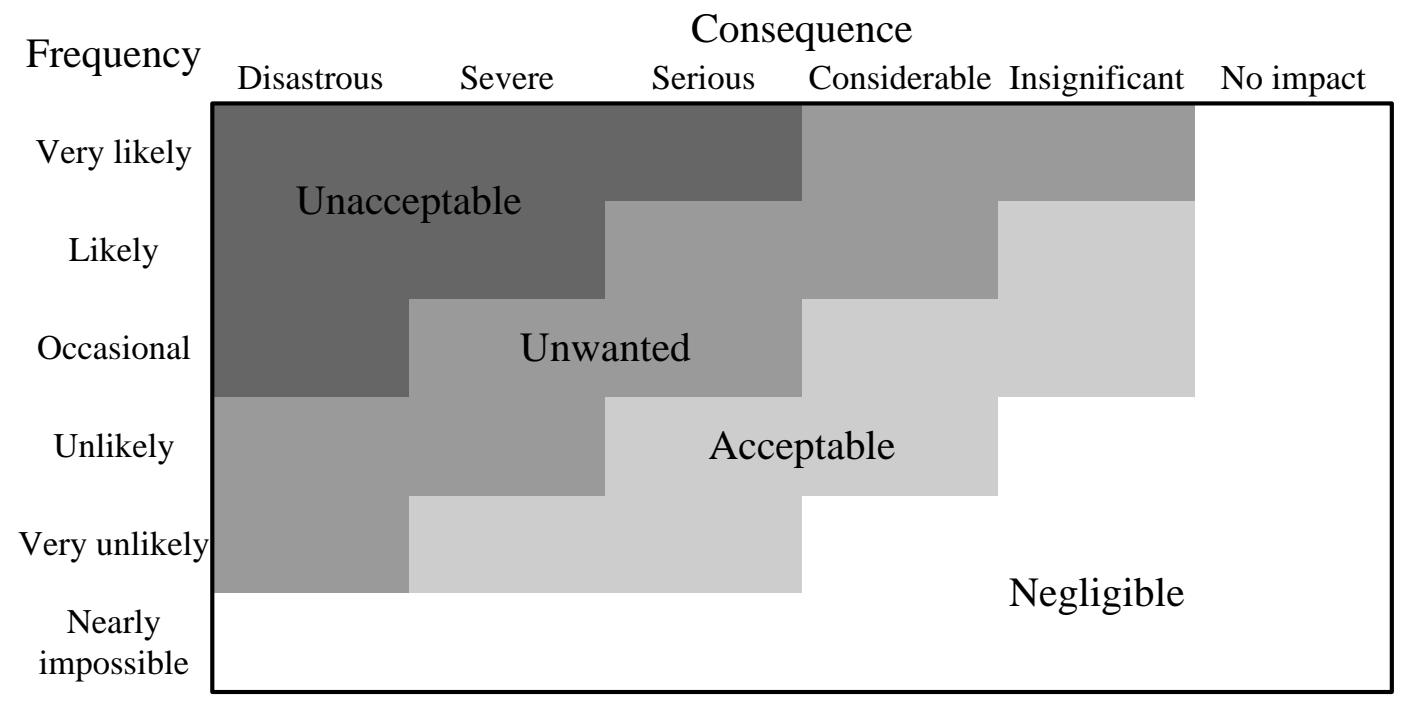


Table 4 - Examples of actions for different risk level (Eskesen et al. (2004)).

\begin{tabular}{ll}
\hline Risk level & Descriptions \\
\hline Unacceptable & $\begin{array}{l}\text { The risk shall be reduced at least to Unwanted regardless of the costs of risk mitig } \\
\text { Unwanted }\end{array}$ \\
& $\begin{array}{l}\text { Risk mitigation measures shall be identified. The measures shall be implemented : } \\
\text { the costs of the measures are not disproportionate with the risk reduction obtained } \\
\text { reasonably practicable (ALARP) principle). }\end{array}$ \\
Acceptable & $\begin{array}{l}\text { The hazard shall be managed throughout the project. Consideration of risk mitigat } \\
\text { required. }\end{array}$ \\
Negligible & No further consideration of the hazard is needed. \\
\hline
\end{tabular}


Figure 12 - Organizational Risk Dynamics Observer (ORDO).

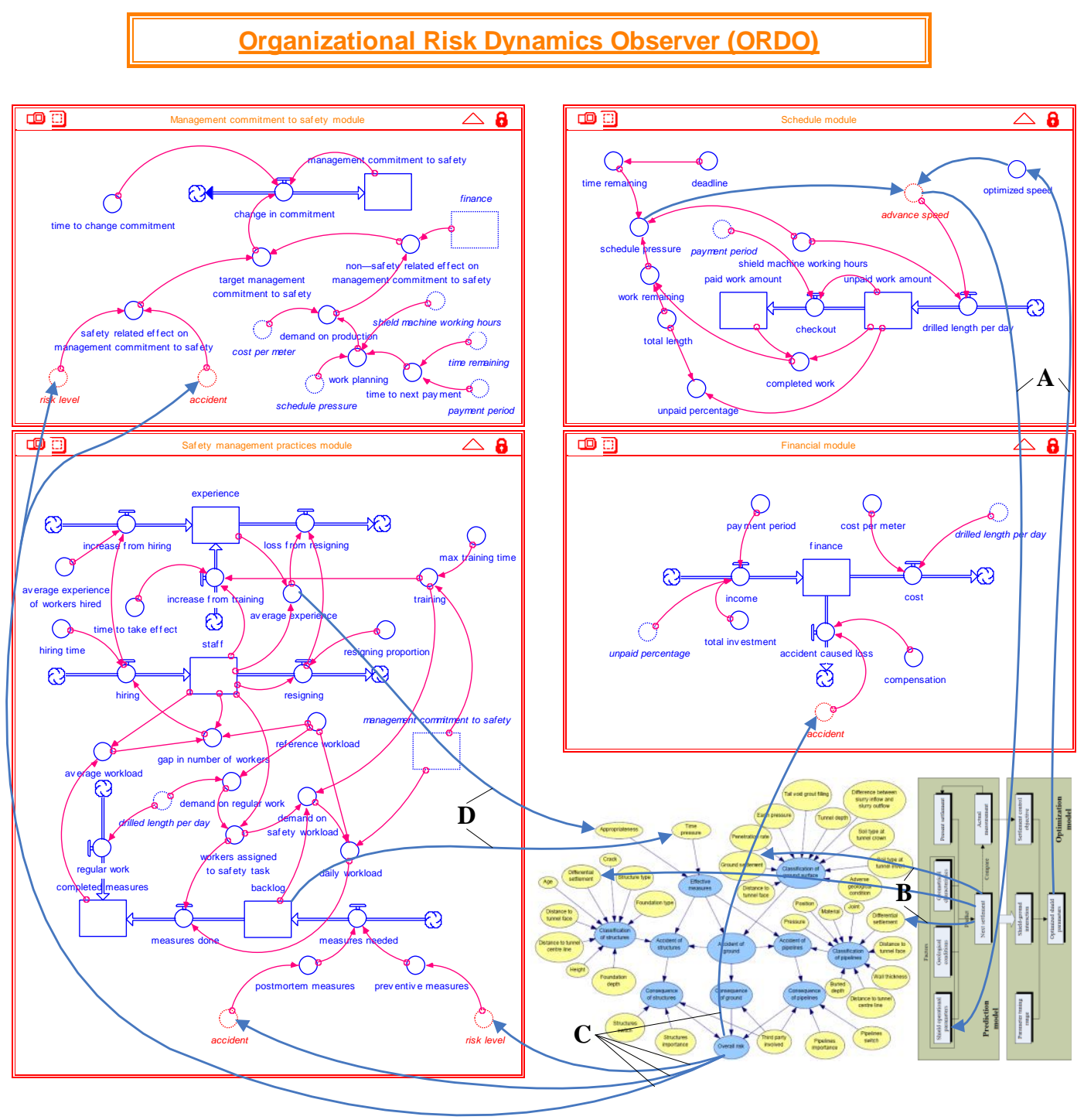


Figure 13 - Schematic diagram of tunneling-induced damages to adjacent structures.

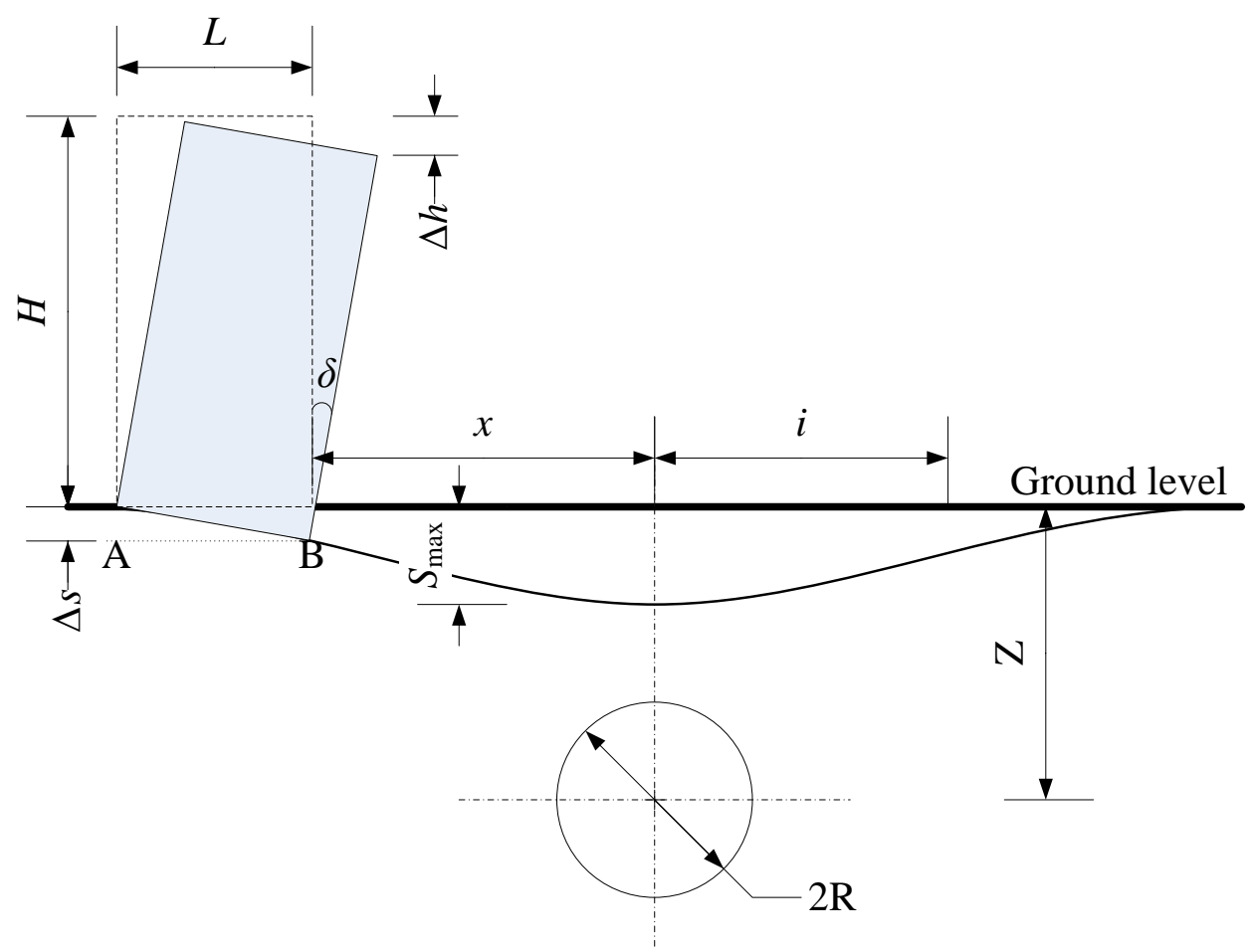


Figure 14 - The organizational schedule performance

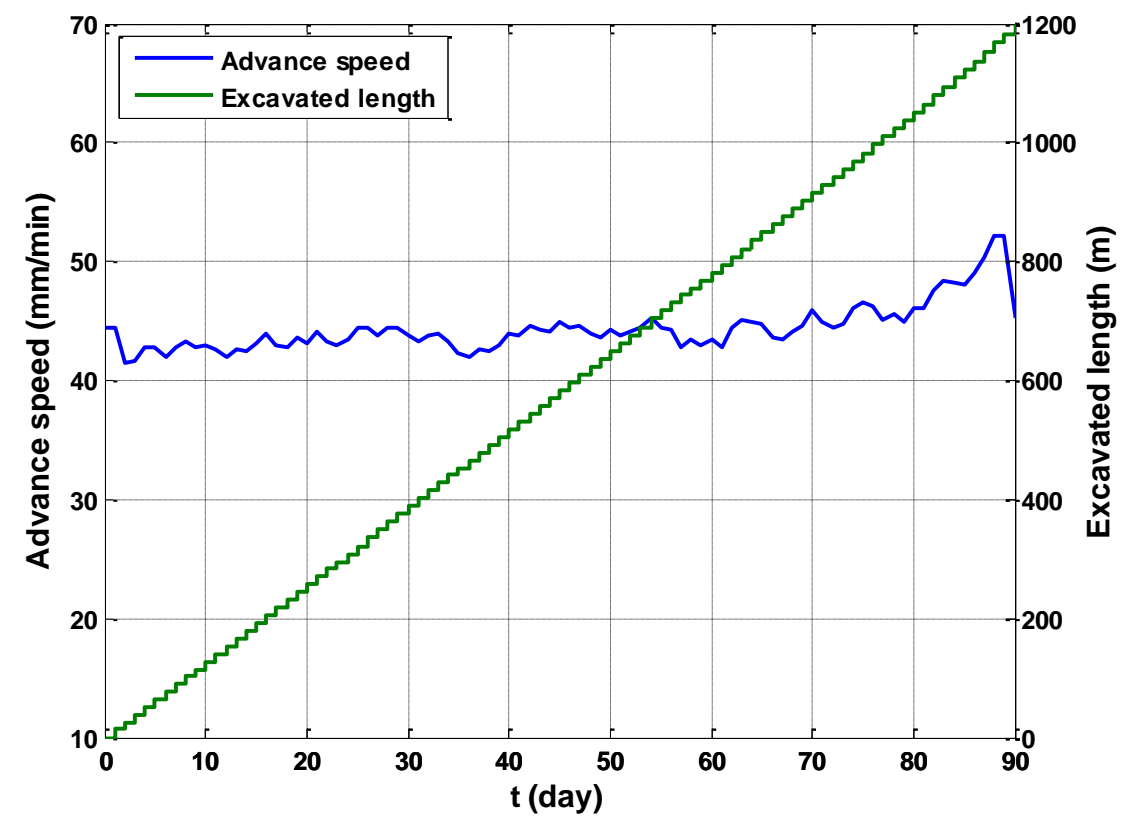


Figure 15 - The project's financial performance

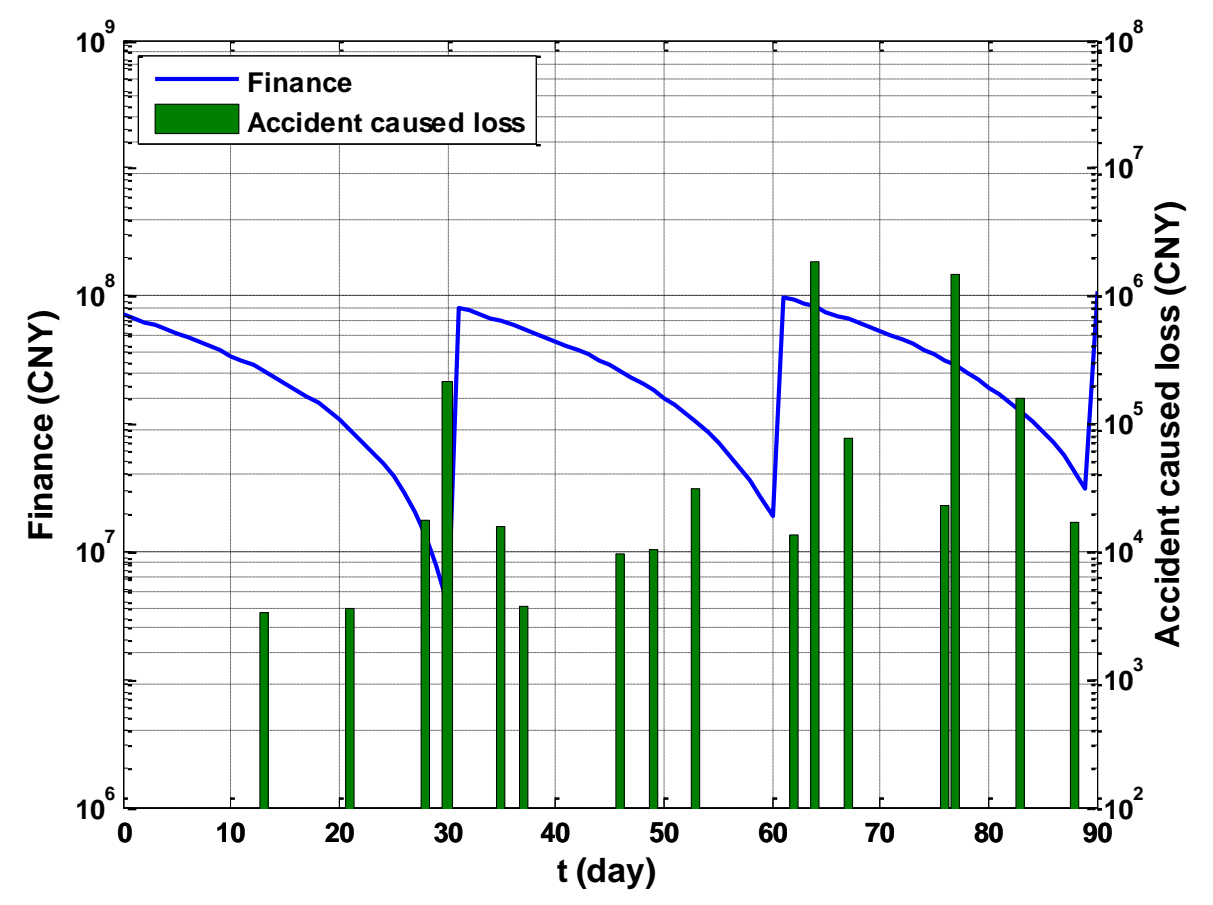


Figure 16 - The organizational safety performance indicators

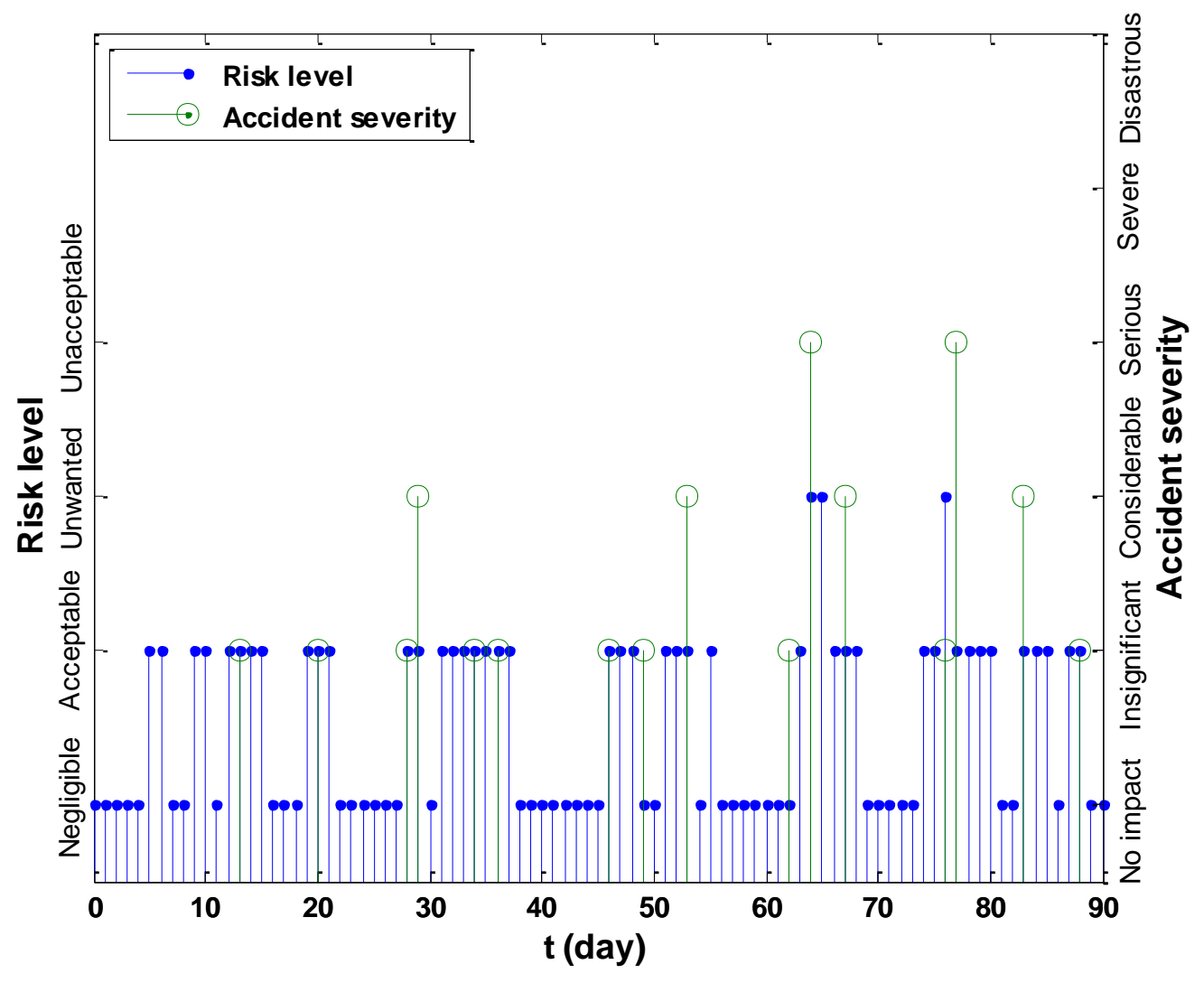


Figure 17 - The spatio-temporal diagram of organizational risk dynamics

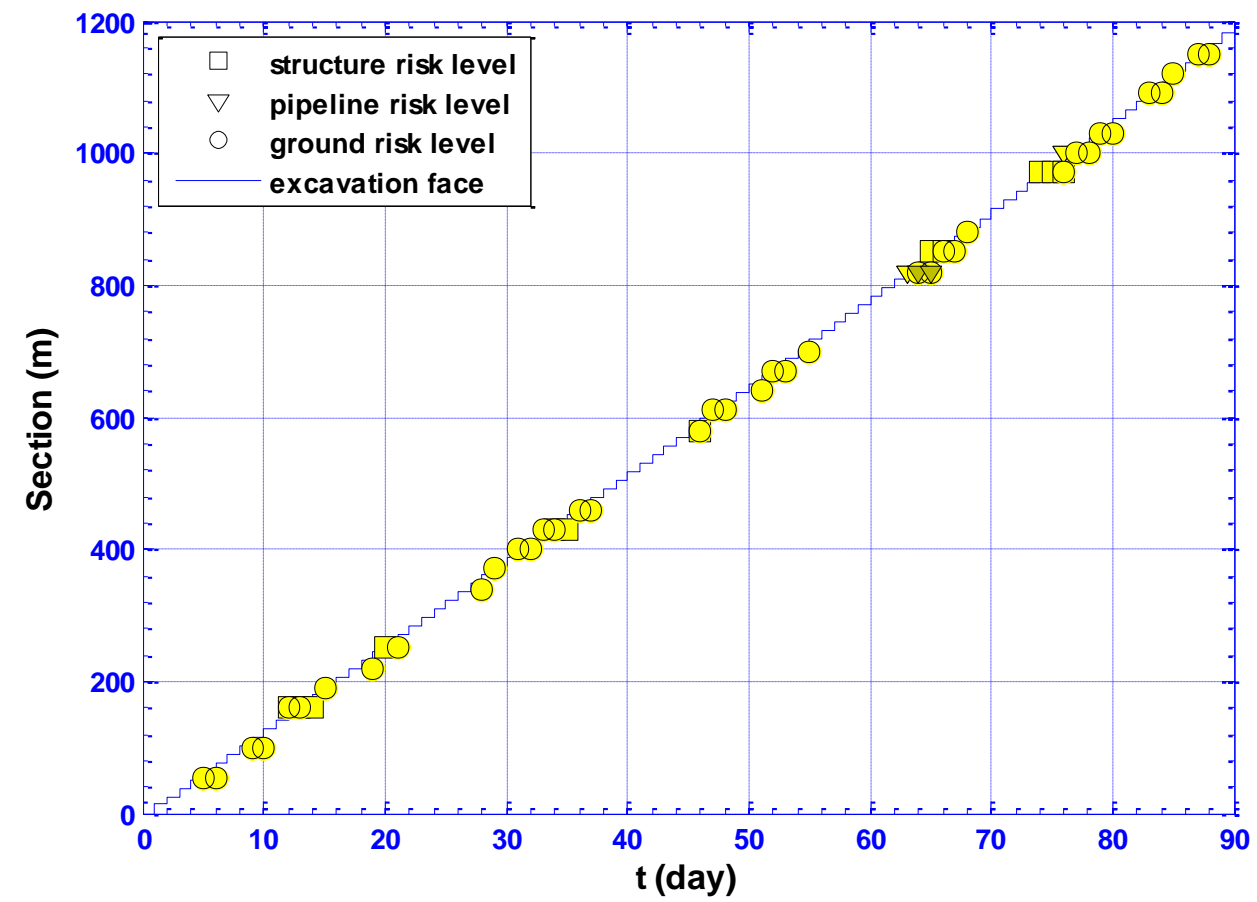


Figure 18 - Management commitment to safety over the construction period

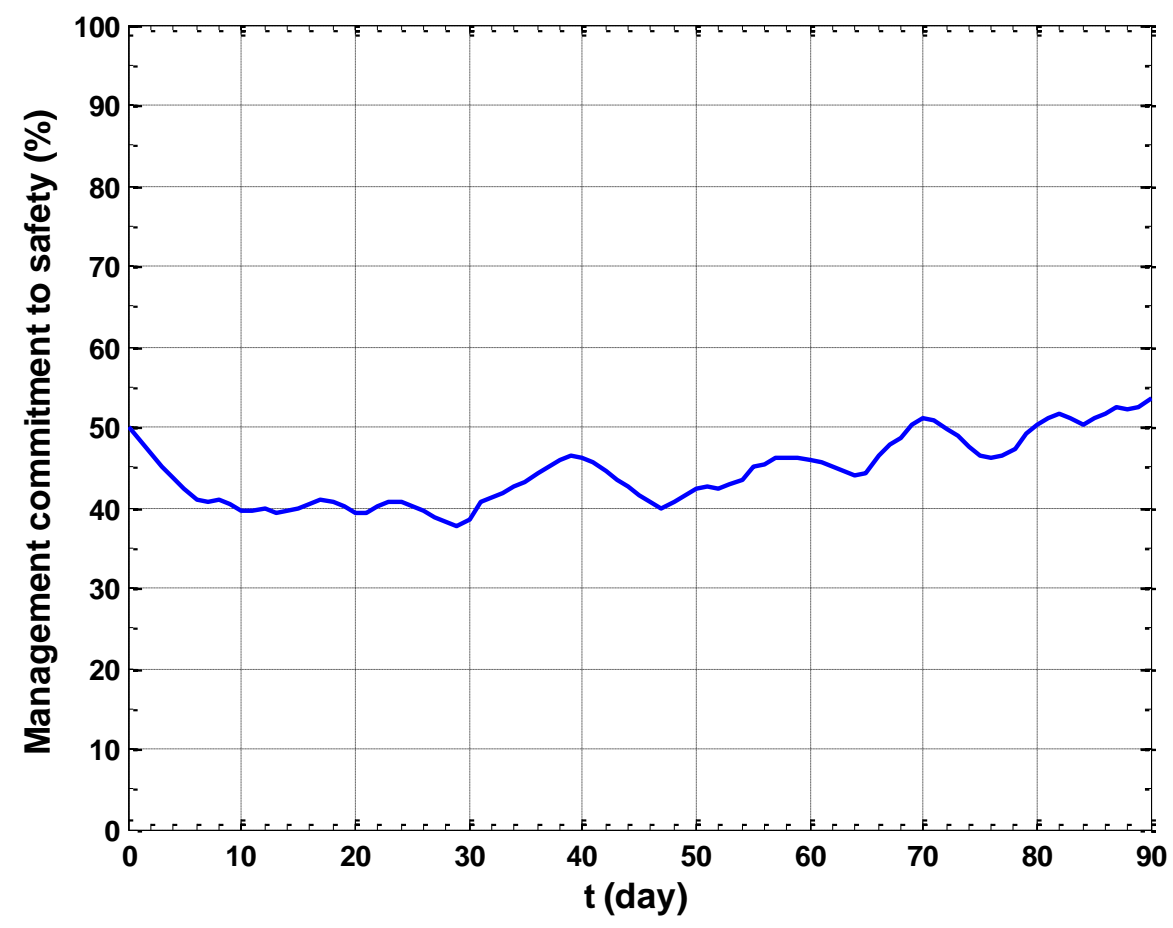


Figure 19 - Variance of average experience

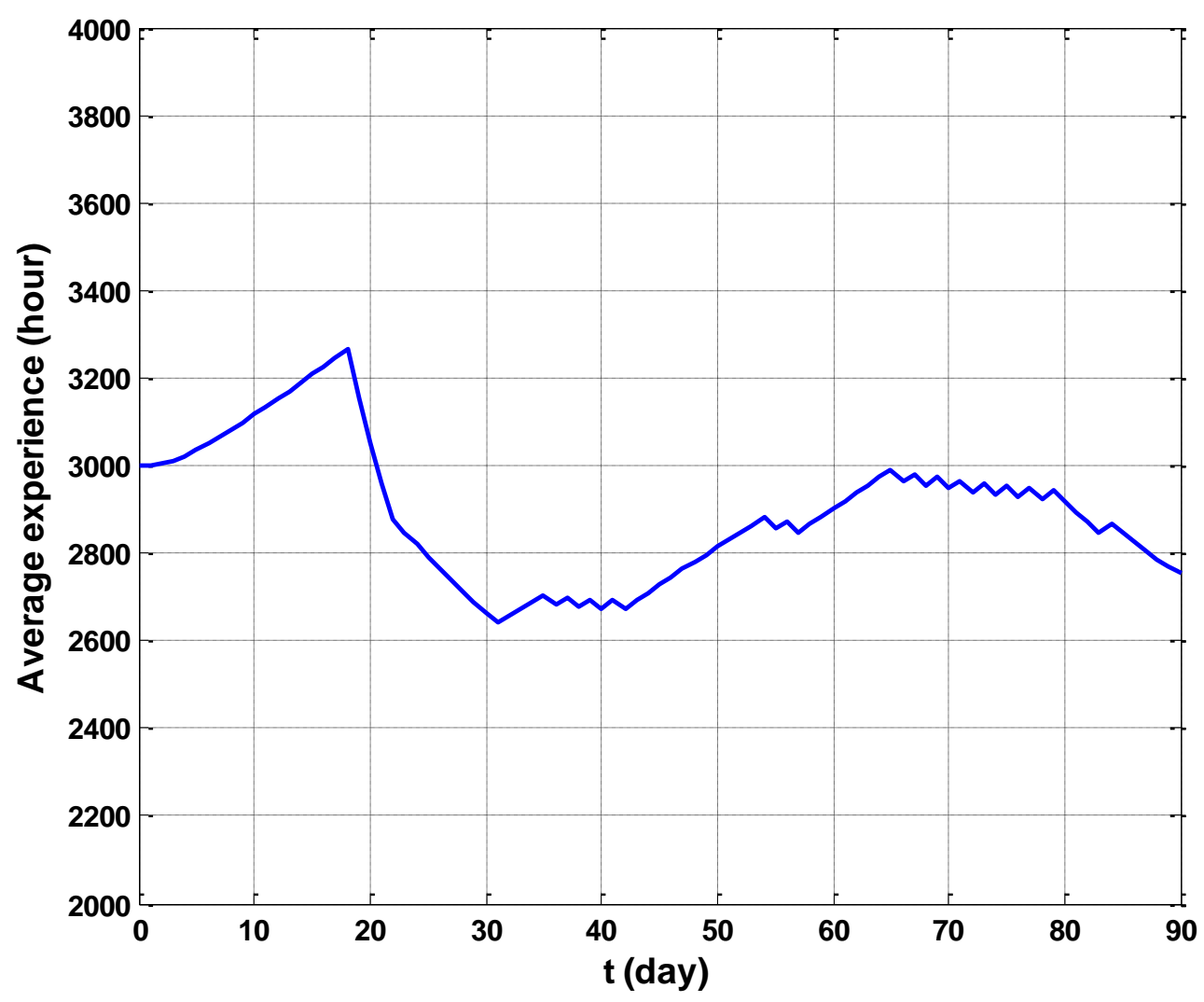


Figure 20 - Backlog of the safety tasks during tunneling

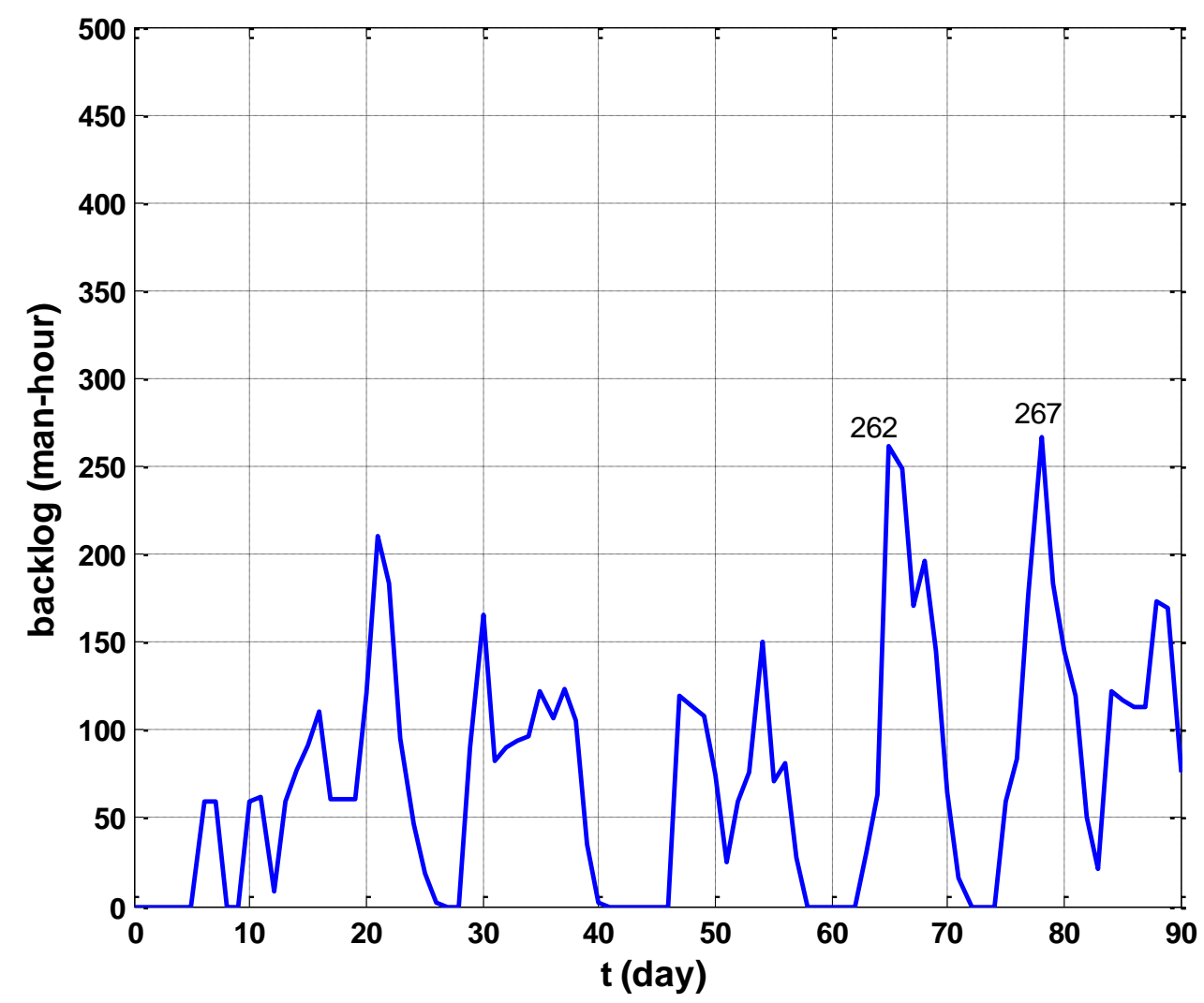

